\title{
Estimation of Initial Abstraction for Hydrological Modeling Based on Global Land Data Assimilation System-Simulated Datasets
}

\author{
YANCHEN ZHENG AND JIANZHU LI \\ State Key Laboratory of Hydraulic Engineering Simulation and Safety, Tianjin University, Tianjin, China \\ LIXIN DONG \\ Tianjin Hydraulic Research Institute, Tianjin, China \\ YOUTONG RONG \\ State Key Laboratory of Hydraulic Engineering Simulation and Safety, Tianjin University, Tianjin, China
}

\section{AIQING KANG}

State Key Laboratory of Simulation and Regulation of Water Cycle in River Basin, China Institute of Water Resources and Hydropower Research, Beijing, China

\section{PING FENG}

State Key Laboratory of Hydraulic Engineering Simulation and Safety, Tianjin University, Tianjin, China

(Manuscript received 4 September 2019, in final form 6 April 2020)

\begin{abstract}
Initial abstraction (Ia) is a sensitive parameter in hydrological models, and its value directly determines the amount of runoff. Ia, which is influenced by many factors related to antecedent watershed condition (AWC), is difficult to estimate due to lack of observed data. In the Soil Conservation Service curve number (SCS-CN) method, it is often assumed that Ia is 0.2 times the potential maximum retention $S$. Yet this assumption has frequently been questioned. In this paper, Ia/S and factors potentially influencing Ia were collected from rainfall-runoff events. Soil moisture and evaporation data were extracted from GLDAS-Noah datasets to represent AWC. Based on the driving factors of Ia, identified using the Pearson correlation coefficient and maximal information coefficient, artificial neural network (ANN)-estimated Ia was applied to simulate the selected flood events in the Hydrologic Engineering Center Hydrologic Modeling System (HEC-HMS) model. The results indicated that $\mathrm{Ia} / S$ varies over different events and different watersheds. Over $75 \%$ of the $\mathrm{Ia} / S$ values are less than 0.2 in the two study areas. The driving factors affecting Ia vary over different watersheds, and the antecedent precipitation index appears to be the most influential factor. Flood simulation by the HEC-HMS model using statistical Ia gives the best fitness, whereas applying ANN-estimated Ia outperforms the simulation with median $\mathrm{Ia} / \mathrm{S}$. For over $60 \%$ of the flood events, ANN-estimated Ia provided better fitness in flood peak and depth, with an average Nash-Sutcliffe efficiency coefficient of 0.76 compared to 0.71 for median Ia/S. The proposed ANN-estimated Ia is physically based and can be applied without calibration, saving time in constructing hydrological models.
\end{abstract}

\section{Introduction}

Watershed runoff generation is a dynamic and complex hydrological process that plays an important role in the formation of flood events. Understanding the relationship between rainfall and runoff is a key issue in the

Corresponding author: Jianzhu Li, lijianzhu@tju.edu.cn management and control of water resources (Balkhair et al. 2018). Runoff is generated by the rainfall that remains after the losses that take place through evaporation, vegetation interception, filling, and infiltration. Generally, the loss of rainfall, including the processes of interception, infiltration, evaporation, and surface depression storage, during the period from the beginning of rainfall to the generation of runoff is termed initial 
abstraction (Ia). The value of Ia is strongly related to climatic and watershed antecedent wetness conditions. The estimation of Ia is of great significance in determining runoff, which influences flood management and forecast.

At present, based on two runoff generation mechanisms, the infiltration-excess (Horton 1933, 1941) and the saturation-excess mechanisms (Dunne 1978; Loague et al. 2010), many methods have been proposed to calculate watershed runoff generation, such as the Green-Ampt method (Green and Ampt 1911), and the Soil Conservation Service curve number (SCSCN) method (SCS 1972). Of all the runoff generation methods, the SCS-CN method, proposed by the USDA Soil Conservation Service, is most widely used because of its relatively few input parameters and simple structure. Soil texture, topographic factors, vegetation condition and land use of the watershed are considered, which makes the SCS-CN method suitable for the estimation of runoff for long-term gauged watersheds as well as ungauged watersheds. Many hydrological models, such as CREAMS (Knisel 1980), AGNPS (Young et al. 1989), SWAT (Arnold et al. 1996), and Hydrologic Engineering Center Hydrologic Modeling System (HECHMS; USACE 2008), employ the SCS-CN method to determine the runoff.

The SCS-CN method makes use of the water balance and two fundamental hypotheses (Mishra et al. 2003). The equations are expressed as follows:

$$
\begin{aligned}
P & =\mathrm{Ia}+F+Q, \\
\frac{Q}{P-\mathrm{Ia}} & =\frac{F}{S}, \quad \text { and } \\
\mathrm{Ia} & =\lambda S,
\end{aligned}
$$

where $P$ is the precipitation $(\mathrm{mm})$; Ia is the initial abstraction $(\mathrm{mm}) ; F$ is the cumulative infiltration excluding Ia $(\mathrm{mm})$, and $F$ is also termed as actual retention, which represents some of the additional rainfall loss after runoff started, mainly in the form of infiltration; $Q$ is the direct runoff depth $(\mathrm{mm}) ; S$ is the potential maximum retention $(\mathrm{mm})$; and $\lambda$ is the initial abstraction ratio. Combining Eqs. (1) and (2), the common form of the SCS-CN method is expressed as Eq. (4):

$$
Q= \begin{cases}\frac{(P-\mathrm{Ia})^{2}}{P+S-\mathrm{Ia}}, & P \geq \mathrm{Ia} \\ 0, & P<\mathrm{Ia}\end{cases}
$$

In the SCS-CN method, Ia is a sensitive parameter that is difficult to acquire from observed data and generally varies from different rainfall-runoff events. However, due to its temporal variation, Ia typically needs to be calibrated for each event in the event-based model, for instance, the HEC-HMS model. Therefore, according to the definition of Ia and the analysis of a large amount of rainfall-runoff event data, the Soil Conservation Service recommends that Ia should be taken as 0.2 times the potential maximum retention $S$ of the watershed, or, in other words, the initial abstraction $\operatorname{ratio}(\lambda=\mathrm{Ia} / S)$ is 0.2 . Nevertheless, this assumption has recently been challenged (Hawkins et al. 2002; Woodward et al. 2003; Shi et al. 2009; Fu et al. 2011; Noori et al. 2012; Hawkins et al. 2019). The Ia/ $S$ value has a significant impact on the accuracy of flood prediction. Hawkins et al. (2002) suggested that $\mathrm{Ia} / S$ is not a constant value; rather, it varies between different storms and different basins. Noori et al. (2012) found that $\mathrm{Ia} / S=0.05$ provides superior results compared to the recommended value of 0.2. Fu et al. (2011) analyzed 757 rainfall-runoff events in Shaanxi and Gansu Provinces to quantify the Ia/S, indicating that the average value of $\mathrm{Ia} / S$ is 0.08 and the median value is 0.05 in the Loess Plateau of China.

As is mentioned above, Ia is related to the rainfall loss through all processes, including evaporation, vegetation interception, infiltration and surface depression storage, during the period from the onset of rainfall to the generation of runoff. Many researchers have begun to study the influence of various potential factors upon Ia. Mishra et al. (2006) held that Ia varies inversely with antecedent moisture and proposed an improved Ia- $S$ relation incorporating antecedent moisture. Lin et al. (2013) proposed an empirical power-function relationship between Ia and initial discharge, which makes hydrological models more useful in flood forecasting. In all of these studies, Ia is understood to be closely related to antecedent watershed conditions. Brocca et al. (2009) utilized the observed soil moisture data to estimate wetness conditions of five nested catchments in central Italy; they also employed two antecedent precipitation indices (API) and one baseflow index (BFI) to estimate wetness conditions for the SCS-CN method. However, there is no observed data on soil moisture content for most watersheds.

In general, soil moisture data can be obtained through site measurement, land surface modeling (LSM) and satellite retrieval (Liu et al. 2019). Yet, the instrumental sites are extremely sparse due to the high cost of maintenance. Accordingly, the application of remotely sensing soil moisture data has become a prevalent method in the field of hydrology for solving the problem of ungauged watersheds in recent years (McDonough et al. 2018; Bhuiyan et al. 2017). Among the various LSM and satellite retrieval soil moisture products, the GLDAS-Noah is representative and has a 
wide range of applications (Wang et al. 2011; Yuan et al. 2015; Wang et al. 2016). Vissa et al. (2019) have predicted the ENSO-induced groundwater changes in India using monthly soil moisture data from GLDAS-Noah datasets. Liu et al. (2019) have utilized soil moisture data from GLDAS-Noah datasets to analyze global drought. In addition to soil moisture data, evaporation data from GLDAS-Noah datasets have also frequently been adopted. Xing et al. (2018), for instance, have applied the evapotranspiration data from GLDAS-Noah datasets to estimate the monthly evapotranspiration across different climatic regions. Given that Ia is related to evaporation and antecedent soil moisture conditions, the soil moisture and evaporation data from GLDASNoah datasets have the potential to predict Ia.

To clarify the relationship between Ia and evaporation, soil moisture and other watershed wetness condition factors, the application of data-driven approaches, which have gained popularity in recent years, can be taken into account (Ouyang et al. 2016). Many datadriven methods, such as the Box-Jenkins method (Box and Jenkins 1970), the support vector machines (SVM) method (Vapnik 1995) and machine learning algorithms have been widely employed to forecast hydrologic variables (Kaur and Jothiprakash 2013). Kumar et al. (2019) have applied recurrent neural network (RNN) and long short-term memory (LSTM) methods for forecasting monthly rainfall. Several similar studies (Moustris et al. 2011; Kashid and Maity 2012; Ramana et al. 2013; Mekanik et al. 2013) have shown the applicability of machine learning algorithms in forecasting rainfall. $\mathrm{Hu}$ et al. (2018) proposed the artificial neural network (ANN) and LSTM approach for flood forecasting, and the results illustrated that both the two networks are suitable for rainfall-runoff models and better than conceptual and physically based models. ANN is a nonlinear statistical data modeling tool, which is often used to capture the complex relationships between input variables and output variables. It has the unique advantages of distributed parallel processing, nonlinear modeling and adaptive learning ability, which provides an effective means of simulating and evaluating the process of nonlinear complex systems. ANN has been applied in many fields, such as classification, pattern recognition and nonlinear modeling (Tayfur et al. 2008). Therefore, ANN is employed to capture the relationship between Ia and its driving factors in this study.

The objectives of this study are 1) to determine the driving factors of Ia by identifying the relationship between Ia and potential driving factors extracted from measured rainfall-runoff events and GLDAS-Noah datasets; 2) to propose an Ia-estimation method, and specifically construct an ANN model to reveal the complex relationship between Ia and its driving factors; and 3) to assess the proposed Ia-estimation method by simulating flood events in the event-based HEC-HMS model to investigate the superiority of ANN-estimated Ia.

\section{Study area and data}

\section{a. Study area}

The verification was performed in the drainage area of the Zijingguan hydrological station and the Wulongji hydrological station, situated in the northeastern part of China. The Zijingguan hydrological station, which controls a $1760-\mathrm{km}^{2}$ watershed area, is in the upstream of the Juma River in the Daqing River basin (Fig. 1a). The length of the main stream is $81.5 \mathrm{~km}$ with an average slope of $5.5 \%$. The climate in the Zijingguan watershed is typical temperate continental and semiarid, with a mean annual precipitation of $650 \mathrm{~mm}$. Flood events in the Zijingguan watershed are mostly generated by rainstorms in flood season.

The Wulongji hydrological station is situated in Chengde County, Hebei Province, the middle reaches of Luanhe River. The Wulongji watershed, with the drainage area of $30100 \mathrm{~km}^{2}$, is located in northeast China, accounting for $67.7 \%$ of the Luanhe River basin area (Fig. 1b). Most of the precipitation is concentrated in July and August, accounting for more than $50 \%$ of the whole year. The annual precipitation of the Wulongii watershed ranges from 885.8 to $338.7 \mathrm{~mm}$ with an average precipitation of $587.8 \mathrm{~mm}$. Location of the hydrological station and rain gauges for the Zijingguan and Wulongii watersheds are shown in Fig. 1.

\section{b. Data collection}

\section{1) RAINFALL-RUNOFF EVENTS SELECTION}

Two datasets were collected from the Zijingguan hydrological station and Wulongi hydrological station. For the first set, hourly flood discharge data at the Zijingguan hydrological station and hourly rainfall data from eight gauges in the Zijingguan drainage area were collected from 1956 to 2014, which include 103 rainfallrunoff events in total. Only 64 rainfall-runoff events were selected in this study. The selection criteria are as follows:

1) A 2-yr return period flood is considered as threshold flow (specifically, $39 \mathrm{~m}^{3} \mathrm{~s}^{-1}$ in the Zijingguan watershed and $44 \mathrm{~m}^{3} \mathrm{~s}^{-1}$ in the Wulongji watershed). A flood with a 2-yr return period, which is often regarded as natural bankfull discharge, is a good alternative for watersheds without a predefined warning level 


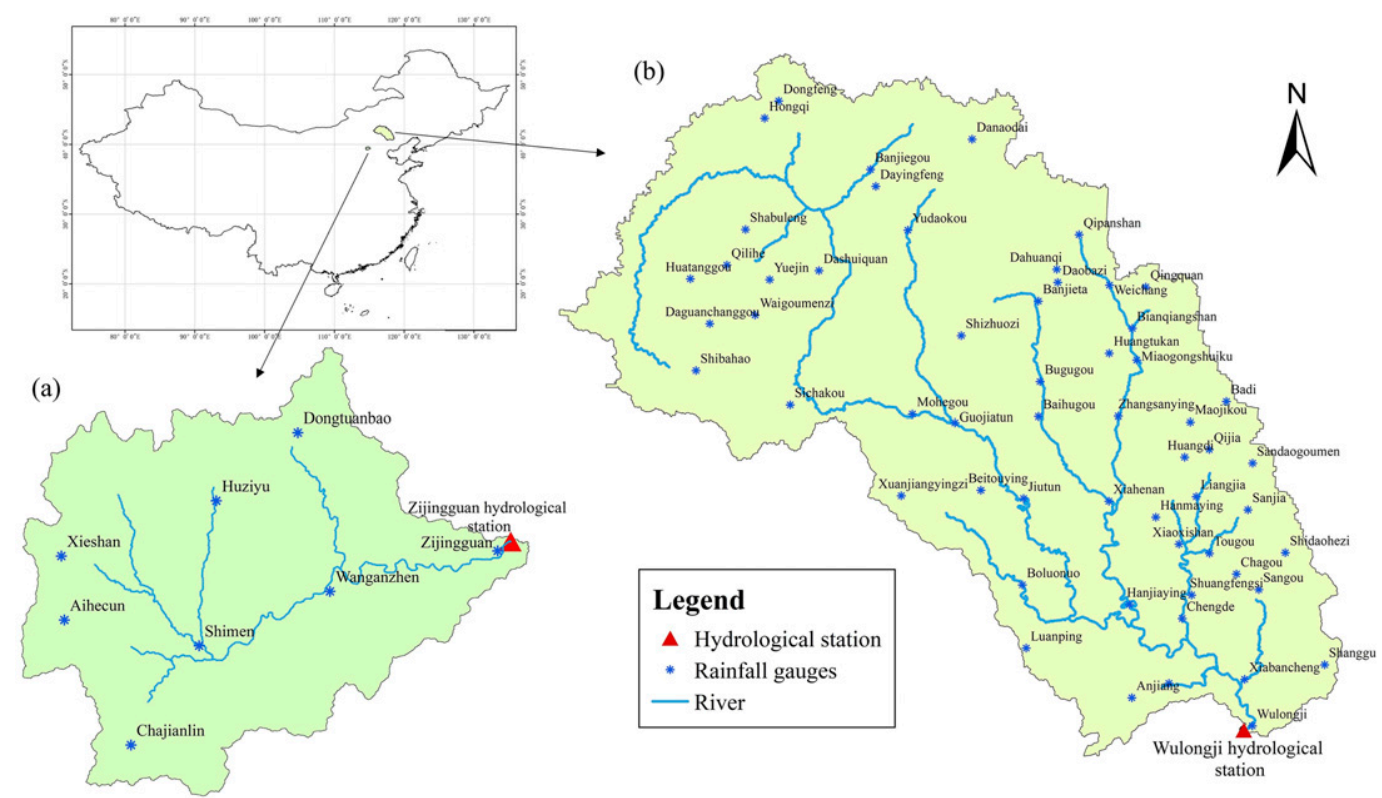

FIG. 1. Location of the hydrological station and rain gauges for the two study areas (a) Zijingguan watershed and (b) Wulongji watershed.

(Weeink 2010) and can even be set as a global minimum flood protection standard (Scussolini et al. 2016). Consequently, a 2-yr return period flood can be regarded as the criterion for determining that floods have occurred, and it symbolizes the magnitude of flood events that can be used for rainfallrunoff event analysis.

2) A 6-h interval, a widely adopted length (Loukas and Quick 1996; Rahman et al. 2002; Manfroi et al. 2004; Baltas et al. 2007), was applied as the interval length to separate the rainfall events, as a long interval length of rainfall events potentially increases the complexity of their effects on runoff because of drying during intraevent rainless periods (Dunkerley 2008). In addition, since with single-peak runoff events can better estimate effective rainfall (Gupta et al. 1986) and avoid uncertainty in determining the peak timing for multipeak events (Tang and Carey 2017), runoff events with multiple peaks have been excluded. Single-peak runoff events are often preferred in conducting rainfall-runoff event analysis (Furey and Gupta 2005; Schwab et al. 2017; Tarasova et al. 2018).

3) Storms satisfying $P / S \leq 0.456$ should be excluded and considered as small storms for SCS-CN application (Hawkins et al. 1985). The use of smaller events could bias the results toward a larger $\mathrm{CN}$ (Woodward et al. 2003; Hawkins et al. 2009; Noori et al. 2012), yet low rainfall events with a high $\mathrm{CN}$ bias can be found in essentially every dataset (Mishra et al.
2007). This criterion, namely, storms satisfying $P / S>0.456$ were selected, guarantees that $90 \%$ of rainfall events will generate runoff in different watershed antecedent moisture conditions and minimizes the upward bias in the determination of $\mathrm{CN}$ (Simanton et al. 1996).

Flood frequency analysis was performed to classify the magnitude of the 64 rainfall-runoff events into four categories (Ministry of Water Resources 2006) according to the return periods $T$ (yr), namely, small floods $(T<5 \mathrm{yr})$, moderate floods $(5<T<20 \mathrm{yr})$, large floods $(20<T<50 \mathrm{yr})$ and extraordinary floods $(T>50 \mathrm{yr})$. Additionally, for small datasets, the ratio for splitting the size of the training and test sets in machine learning is usually determined as $80 / 20$, where $80 \%$ of the data are allocated for training and $20 \%$ for testing (Shan 2016). Thus, 14 out of the 64 rainfall-runoff events, including all the flood categories, were selected to construct the HEC-HMS model and used as the test datasets for the ANN model. The remaining 50 rainfall-runoff events were employed to determine the statistical Ia and to train the ANN model.

For the Wulongji watershed, hourly flood discharge data and the corresponding rainfall data from 57 rain gauges from 1992 to 2014 were collected, including 67 rainfall-runoff events. According to the selection criteria and flood frequency analysis, 42 rainfall-runoff events were selected in this study, including 10 events for the HEC-HMS model simulation (test datasets of ANN 
TABLE 1. Potential driving factors of Ia.

\begin{tabular}{rllllc}
\hline \hline No. & \multicolumn{1}{c}{ Factors } & Abbreviation & \multicolumn{1}{c}{ Unit } & Data source & Data collection time \\
\hline 1 & Soil moisture content of $0-10 \mathrm{~cm}$ & SM0_10 & $\mathrm{kg} \mathrm{m}^{-2}$ & GLDAS-Noah & A time step before the \\
2 & Soil moisture content of $10-40 \mathrm{~cm}$ & SM10_40 & $\mathrm{kg} \mathrm{m}^{-2}$ & & rainfall event \\
3 & Soil moisture content of $40-100 \mathrm{~cm}$ & SM40_100 & $\mathrm{kg} \mathrm{m}^{-2}$ & \\
4 & Soil moisture content of $100-200 \mathrm{~cm}$ & SM100_200 & $\mathrm{kg} \mathrm{m}^{-2}$ & From the beginning of the \\
5 & Root zone soil moisture & RZSM & $\mathrm{kg} \mathrm{m}^{-2}$ & rainfall to the start of \\
6 & Evapotranspiration & EV & $\mathrm{kg} \mathrm{m}^{-2} \mathrm{~s}^{-1}$ & GLDAS-Noah & runoff generation \\
7 & Potential evaporation rate & PET & $\mathrm{W} \mathrm{m}^{-2}$ & \\
8 & Direct evaporation from bare soil & DEBS & $\mathrm{W} \mathrm{m}^{-2}$ & \\
9 & Canopy water evaporation & CWE & $\mathrm{W} \mathrm{m}^{-2}$ & \\
10 & Transpiration & TR & $\mathrm{W} \mathrm{m}^{-2}$ & \\
11 & Antecedent precipitation index & API & $\mathrm{Mm}^{-1}$ & Observed rainfall-runoff events \\
12 & Maximum rainfall intensity & MRI & $\mathrm{mm} \mathrm{h}^{-1}$ & \\
13 & Average rainfall intensity & ARI & $\mathrm{mm} \mathrm{h}^{-1}$ & \\
14 & Initial discharge & ID & $\mathrm{m} \mathrm{m}^{3} \mathrm{~s}^{-1}$ &
\end{tabular}

model) and 32 events for Ia statistical analysis (training datasets of ANN model), respectively.

\section{2) GLDAS DATA COLLECTION}

The related antecedent watershed conditions data, such as soil moisture content and evaporation, were extracted from GLDAS-Noah datasets (Rodell et al. 2004; Beaudoing et al. 2015). NASA Global Land Data Assimilation System (GLDAS) ingests satellite and ground-based observational data products using advanced land surface modeling and data assimilation techniques. GLDAS-Noah land surface state and flux products are provided by the Hydrology Data and Information Services Center (HDISC), a component of the NASA Goddard Earth Sciences Data and Information Services Center (GES DISC). GLDAS-Noah v2.0 currently covers the period from January 1948 to December 2014 (updated at 27 November 2019) and contains 36 parameters, with a 3 -h temporal interval and $0.25^{\circ}$ spatial resolutions. Soil moisture and evaporation data from the GLDAS-Noah datasets were used in this paper because they are closely related to Ia. The potential driving factors of Ia adopted in this study are listed in Table 1.

Figure 2 presents the spatial distribution of soil moisture content grid data from GLDAS-Noah datasets. The center point value of each grid cell represents the average value of its grid. The area-weighted method was adopted to calculate the average soil moisture content and evaporation value of the entire watershed for the gridded data, expressed as Eq. (5):

$$
\bar{V}=\sum_{i=1}^{n} \frac{A_{i}}{A} V_{i},
$$

where $\bar{V}$ represents the average value of the entire watershed; $V_{i}$ is the value of each grid; $A$ is the area of the entire watershed; $A_{i}$ is the area of each grid inside the watershed; $n$ is the number of grids involved in the watershed boundary. Accordingly, the spatial average values for soil moisture content and evaporation for the study area can be extracted.

The soil moisture content data from one time step before rainfall were used to represent antecedent soil moisture conditions, which are available with a 3-h temporal interval. For evaporation data and rainfall characteristics, including antecedent precipitation index (API), maximum rainfall intensity (MRI), and average rainfall intensity (ARI), the data collection time is the period from the beginning of the rainfall to the start of runoff generation. API, MRI, ARI, and initial discharge (ID) were collected by analyzing observed rainfallrunoff events. API represents the summation of daily precipitation amounts over the 5 days before the selected rainfall-runoff events (Sahu et al. 2007; Brocca et al. 2009; Singh et al. 2015).

\section{3) LAND USE AND LAND COVER DATA}

The land use and land cover (LULC) maps for the Wulongji watershed for the years 1992, 1995, and 2014 were obtained from the European Space Agency (ESA) Climate Change Initiative (CCI) (http://maps.elie.ucl.ac.be/ $\mathrm{CCI} /$ viewer/), which provides the global LULC maps ranging from 1992 to 2014. Yet, the earlier LULC maps for the Zijingguan watershed are needed. Accordingly, the LULC data for the Zijingguan watershed for the years 1980, 1995, and 2015 were collected from the Institute of Geographic Sciences and Resources of the Chinese Academy of Sciences (http://www.resdc.cn/), which provides the LULC maps of China for every 5 years beginning in 1980. Harmonized World Soil Database (HWSD) v1.1 soil data of the year 1995 were utilized to extract the soil groups for the two study areas. 


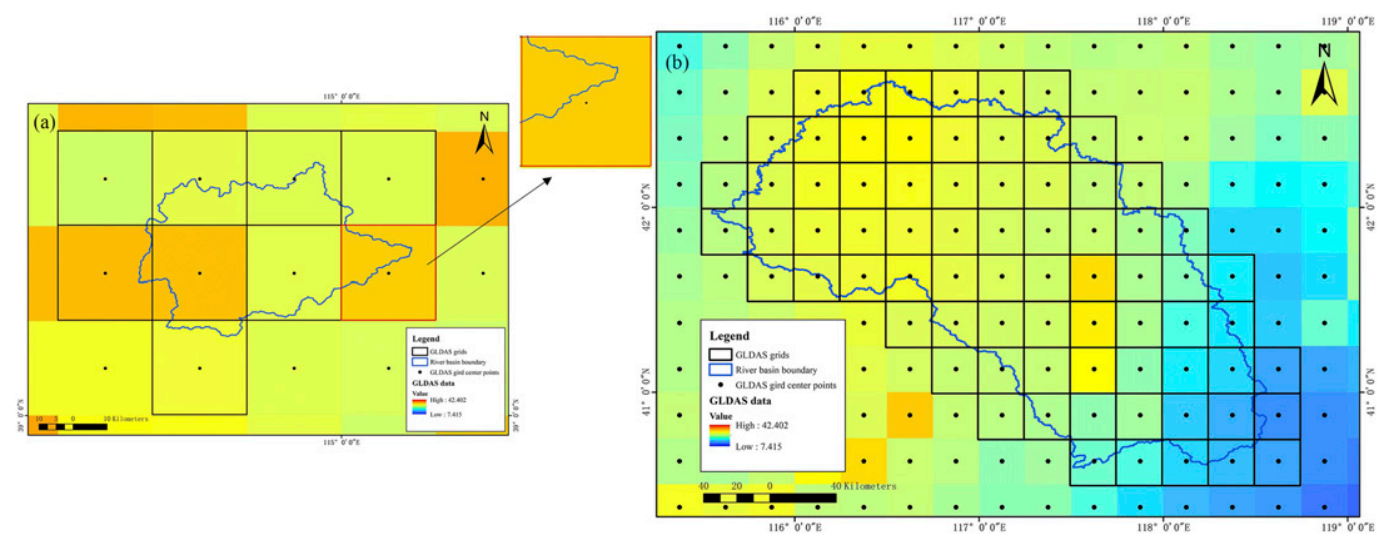

FIG. 2. GLDAS-Noah soil moisture grid data in the watersheds (a) Zijingguan watershed and

(b) Wulongji watershed.

\section{Methods}

The framework of the proposed Ia-estimation method and the assessment method is shown in Fig. 3.

\section{a. Collection of Ia and its driving factors}

\section{1) Calculation of IA/S}

The procedures for determining the Ia/ $S$, namely, the $\lambda$ value, for each rainfall-runoff event are as follows.

According to Eq. (4), the parameter $S$ can be written in Eq. (6):

$$
S=\frac{(P-\mathrm{Ia})^{2}}{Q}-(P-\mathrm{Ia})
$$

Intuitively, $S$ can be acquired using the rainfall $(P)$, the direct runoff $(Q)$, and the initial abstraction (Ia).
The first curial step is separating the baseflow to obtain the direct runoff hydrograph. Thus, synchronized hourly rainfall and runoff data were required. The rainfall depth when direct runoff began was taken as Ia. The start time of direct runoff is defined as the time when the gradient of direct runoff hydrograph changes abruptly (Fischer et al. 2016). After that, with the known values of $Q$, Ia, and $P, S$ can be derived using Eq. (6). Finally, $\lambda$ for each rainfall-runoff event was obtained by calculating Ia/ $S$.

A MATLAB toolbox proposed by Tang and Carey (2017), namely, HydRun, was employed to separate the baseflow from the hydrograph. It is based on the recursive digital filter technique proposed by Nathan and McMahon (1990), as expressed in Eqs. (7) and (8). Among numerous different baseflow separation approaches, the filtering separation method is one of the most frequently used methods:

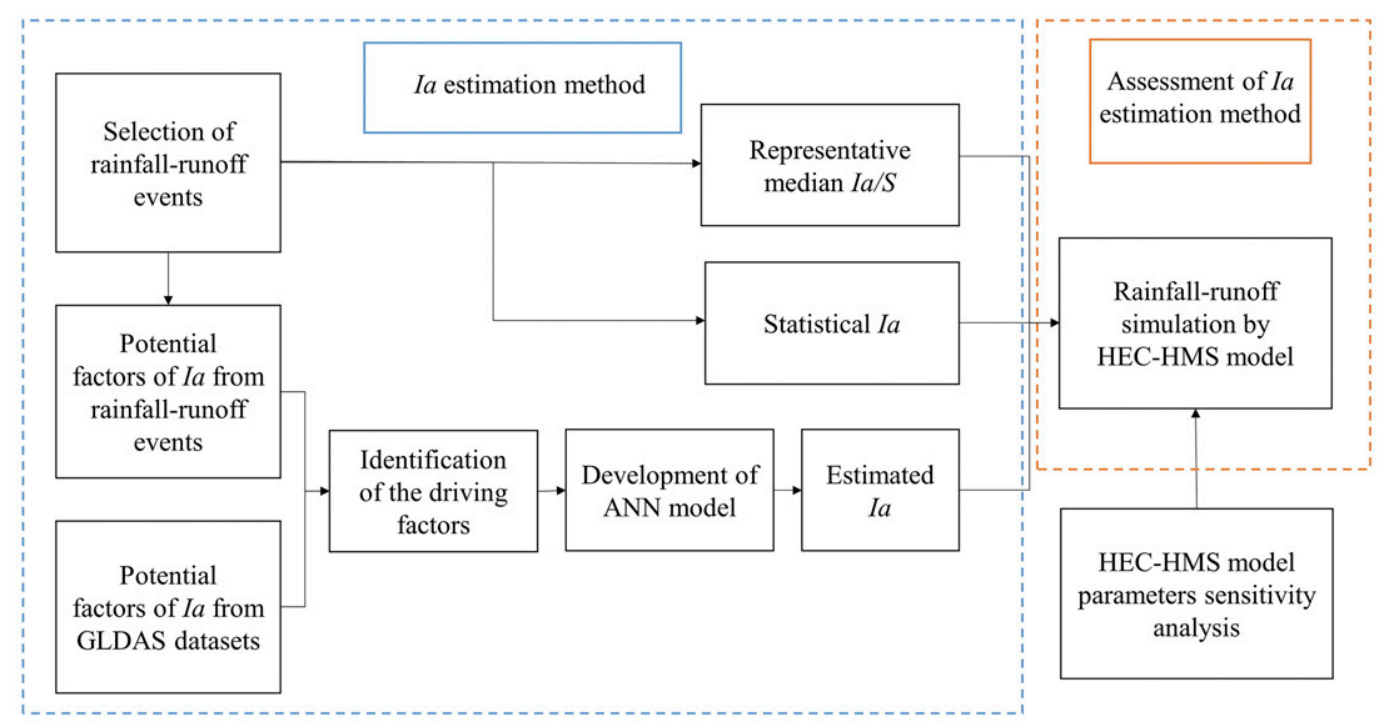

FIG. 3. Framework of the Ia-estimation method and the assessment method adopted in this study. 


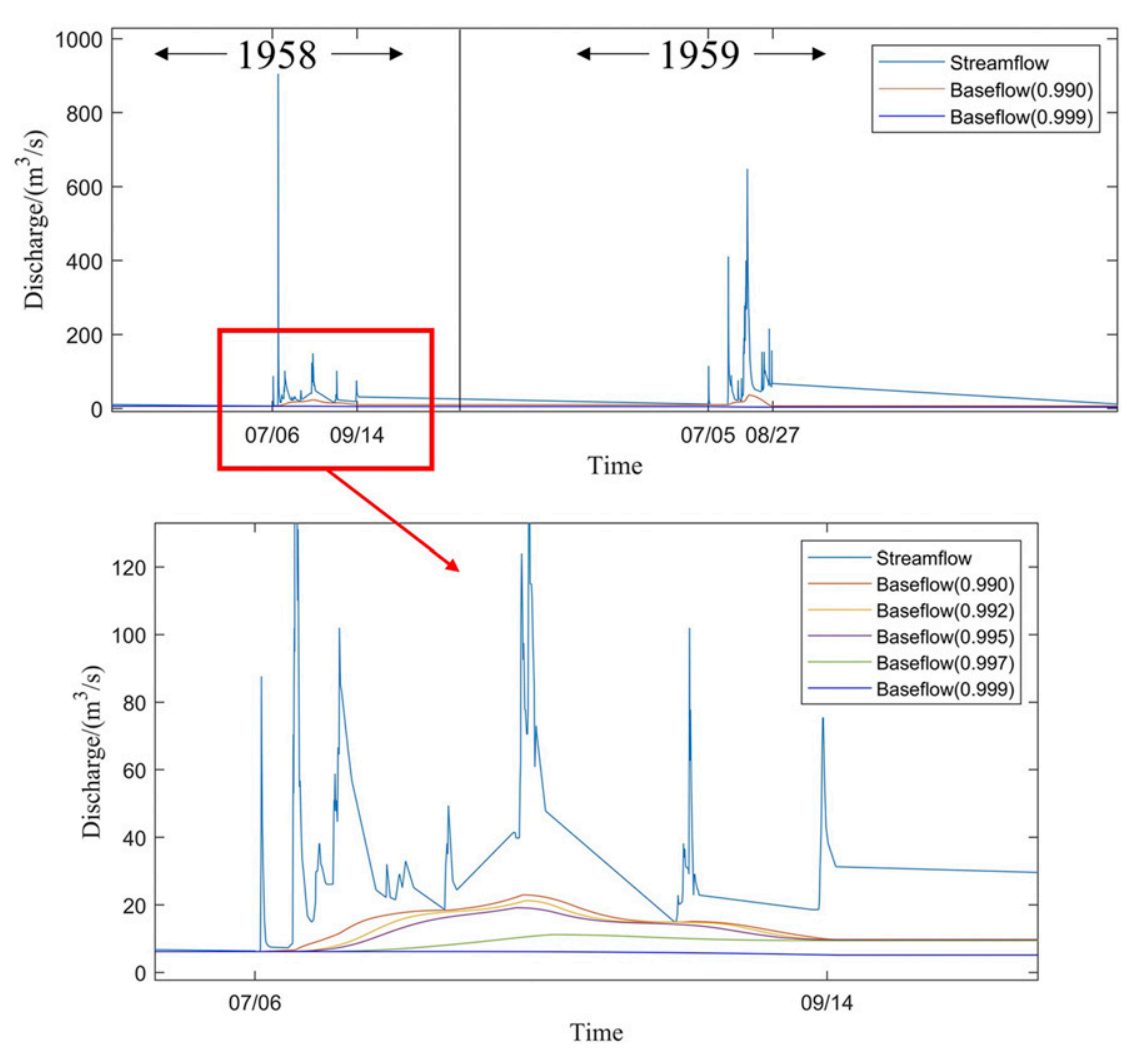

FIG. 4. Sensitivity of $\beta$ varied between 0.990 and 0.999 for the Zijingguan watershed.

$$
\begin{aligned}
& b_{t}=\beta b_{t-1}+\frac{1-\beta}{2}\left(Q_{t}+Q_{t-1}\right), \\
& q_{t}=Q_{t}-b_{t}
\end{aligned}
$$

where $b_{t}$ is the filtered baseflow at time $t, \beta$ is the filter coefficient, $Q_{t}$ is the original flow discharge, and $q_{t}$ is the direct runoff.

The filter coefficient $\beta$, generally ranging from 0.990 to 0.999 , affects the baseflow separation. If a low-filter coefficient was applied, the shape of filtered baseflow more closely followed the hydrograph and became increasingly more muted with increasing $\beta$. Figure 4 illustrates the sensitivity of $\beta$ varied between 0.990 and 0.999 for the Zijingguan watershed during 1958-59. Eventually, a filter coefficient $\beta$ of 0.995 was selected for both of the two study areas.

\section{2) IDENTIFICATION OF THE DRIVING FACTORS AFFECTING IA}

To explore the correlation between Ia and its driving factors, Pearson correlation coefficient (PCC) and maximal information coefficient (MIC) were employed. The PCC method is based on linear correlation, as shown in Eq. (9):

$$
r=\frac{\sum(x-\bar{x})(y-\bar{y})}{\sqrt{\sum(x-\bar{x})^{2} \sum(y-\bar{y})^{2}}},
$$

where $r$ denotes the Pearson correlation coefficient; $x$ represents the factors affecting Ia; and $y$ is the value of Ia. The absolute value of $r$ is between 0 and 1 . A negative value of $r$ represents the value of $y$ decreases with the increase of $x$.

The PCC method only measures the linear correlation between two variables. However, the relationship between Ia and its driving factors remains unclear. The MIC method is capable of capturing multiple kinds of associations, including linear, nonlinear and nonfunctional relations (Bai et al. 2019). The MIC method, proposed by Reshef et al. (2011), is based on the idea that if a relationship exists between two variables, then a grid can be drawn on the scatterplot of the two variables. The distribution of the data in the grid can reflect their relationship. The MIC value of a pair of data series $x$ and $y$ is defined in Eq. (10):

$$
\operatorname{MIC}(D)=\max _{X Y<B(n)} M(D)_{X, Y}=\max _{X Y<B(n)} \frac{I(D, X, Y)}{\log _{2} \min (X, Y)}
$$




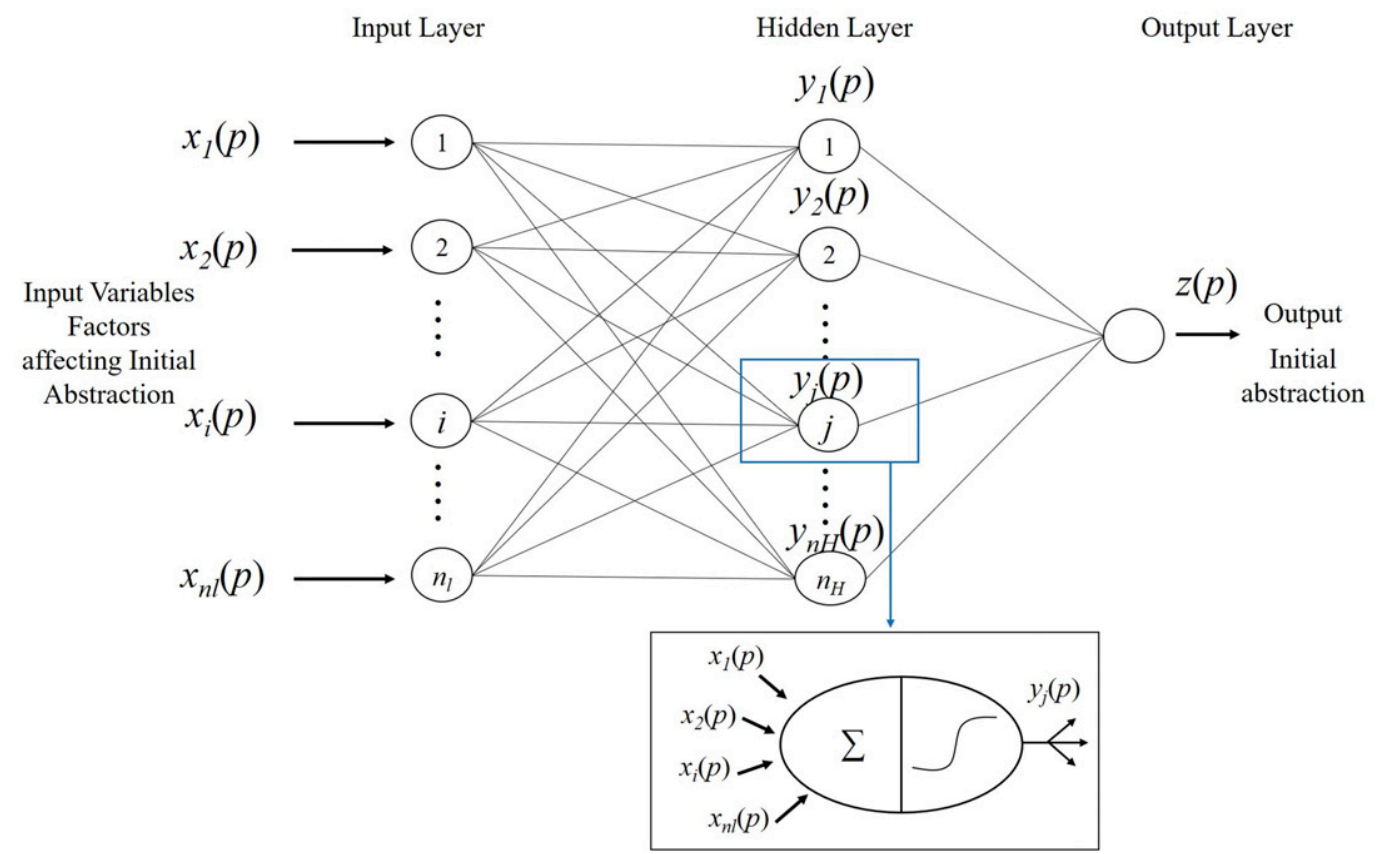

FIG. 5. Schematic diagram of artificial neural network employed in this study.

where $D=(x, y)$ is the set of $n$ ordered pairs of elements of $X$ and $Y$. The ordered pairs $(x, y)$ divide the $X, Y$ plane into several small cells, namely, the $X \times Y$ grid. The term $I(D, X, Y)$ is the maximum mutual information over all $X \times Y$ grids; $B(n)=n^{\alpha}$ is a function of sample size $n$, and we usually set $B(n)=n^{0.6}$.

Hence, the MIC method could play a role in judging the dependence relationship between Ia and its driving factors. The range of the MIC is also between 0 and 1 . The higher the absolute value of the PCC and the MIC, the greater the correlation between Ia and its driving factors.

The analytical hierarchy process (AHP), one of the most widely used tools for decision-making (Saaty 1977), is employed to arrange the factors based on the value of PCC and MIC. Four main procedures were involved in the AHP process. First, a hierarchy structure is built, namely, PCC and MIC were chosen as criterion layers. Then, according to the value of PCC and MIC, the pairwise comparisons between 14 potential driving factors were carried out to develop the comparison matrices. After that, the local and global weights can be derived by adopting an eigenvector method. The last step is to apply a consistency check.

\section{b. Development of artificial neural network}

\section{1) DESCRIPTION OF ARTIFICIAL NEURAL NETWORK}

The ANN model is adopted as an efficient tool to reveal nonlinear relationships between inputs and outputs. The ANN model is commonly composed of an input layer, a hidden layer, and an output layer. Figure 5 displays the structure of the three-layer feed-forward type of ANN used in this study.

In an ANN model, the basic units of computation are called nodes. Each layer contains several nodes, which receive the input variables or the outputs of nodes of the previous layer, known as weighted inputs. The effective weighted inputs $S_{j}$ is the weighted sum of all the weighted inputs, which can pass through an activation function. The rectified linear unit (ReLU) function is used as the activation function. The output $y_{j}$ of a node $j$ is computed according to Eqs. (11)-(13):

$$
\begin{aligned}
S_{j} & =\sum_{i=1}^{n} w_{j i} x_{i}, \\
y_{j} & =f\left(S_{j}\right), \quad \text { and } \\
f(x) & =\max (0, x),
\end{aligned}
$$

where $S_{j}$ denotes the activation value of node $j$, $w_{j i}$ represents the weight of the $i$ th input and the node $j$ of the layer, $x_{i}$ is the $i$ th input value, $y_{j}$ is the output of the node $j$, and $f(x)$ denotes the activation function.

\section{2) Model DEVELOPMENT}

The flowchart of the ANN model developed in this study is shown in Fig. 6. After selecting the input 


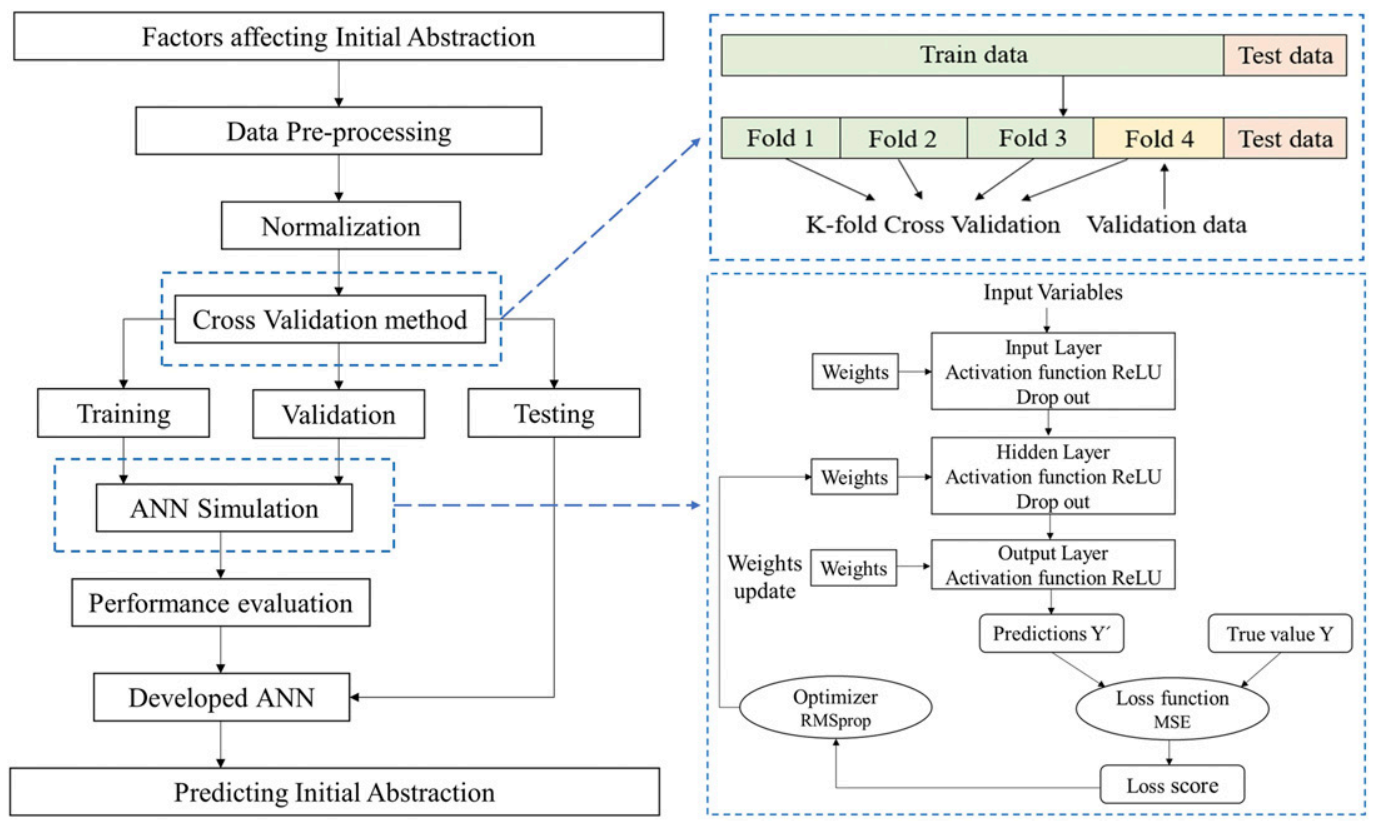

FIG. 6. Flowchart of the ANN model developed in this study.

parameters, the zero-mean normalization method was employed to preprocess the data, as shown in Eq. (14):

$$
x^{*}=\frac{(x-\mu)}{\sigma},
$$

where $x^{*}$ denotes the normalized values of variables, $x$ is the observed variables, $\mu$ is the mean value of all observed variables, and $\sigma$ is the standard deviation of all observed variables.

The input data are usually divided into training datasets and validation datasets. However, when the amount of source data is small, the number of validation datasets becomes even smaller, which leads to great differences in the evaluation results on the validation datasets. The evaluation results are thus not reliable. Consequently, the $K$-fold cross validation method (Ling et al. 2019) was adopted to divide the datasets into training data and validation data. In the process of the training model, $K$-fold cross validation divides the datasets into $K$ parts. One group of datasets is set as the validation datasets, while the remaining $K-1$ parts act as the training datasets. The final evaluation results are the average value of $K$-fold evaluation scores. In this study, the selected 14 and 10 flood events from four categories in the Zijingguan and Wulongji watersheds, respectively, were utilized as test datasets, which were also applied to build the HEC-HMS model. The corresponding data from the rest rainfall-runoff events were used as training datasets, which were divided into training datasets and validation datasets using the $K$-fold cross validation method and computed in the ANN model. Note that the selected flood events for building the HEC-HMS model were not used as ANN model training datasets.

The ANN model was implemented using TensorFlow and Keras, from the Python deep learning library (Chollet 2016). A three-layer ANN model was employed, with each layer adopting ReLU as the activation function. To avoid the overfitting problem, the dropout method was utilized in the input and hidden layers. Mean square error and RMSprop were chosen as the loss function and optimizer, respectively. The number of epochs should be set cautiously to prevent overfitting or underfitting. In the training and validation process, the initial value of epochs was set as 100 . The number of epochs for the test process is based on the performance of the training and validation evaluation. The different cases, composed of different input factors, were all trained in the ANN model using the same process to explore the most significant factors affecting Ia. After determining the number of driving factors and the welltrained ANN model, the test datasets were utilized to estimate Ia.

\section{3) Performance evaluation metrics}

To investigate the performance of the proposed ANN model, four statistical indicators were employed to guarantee the best fitness between estimated value 
and true value. The statistical indicators of mean absolute error (MAE), correlation coefficient (CR), root-meansquare error (RMSE), and Nash-Sutcliffe efficiency coefficient (NSE) are shown in Eqs. (15)-(18). The NSE value illustrates the proximity between predicted and measured values:

$$
\begin{aligned}
\text { MAE } & =\left(\frac{100}{n} \sum_{i=1}^{n}\left|\frac{O_{i}-E_{i}}{O_{i}}\right|\right), \\
\mathrm{CR} & =\left[\frac{\sum_{i=1}^{n}\left(E_{i}-\overline{E_{i}}\right)\left(O_{i}-\bar{O}_{i}\right)}{\sqrt{\sum_{i=1}^{n}\left(E_{i}-\bar{E}_{i}\right)^{2} \sum_{i=1}^{n}\left(O_{i}-\bar{O}_{i}\right)^{2}}}\right], \\
\mathrm{RMSE} & =\sqrt{\frac{\sum_{i=1}^{n}\left(E_{i}-O_{i}\right)^{2}}{n}, \text { and }} \\
\mathrm{NSE} & =\left[\begin{array}{c}
\sum_{i=1}^{n}\left(E_{i}-O_{i}\right)^{2} \\
\sum_{i=1}^{n}\left(O_{i}-\bar{O}_{i}\right)^{2}
\end{array}\right],
\end{aligned}
$$

where $E_{i}$ is the $i$ th network-estimated Ia; $O_{i}$ is the $i$ th statistical calculated Ia; $\bar{E}_{i}$ is the average of the estimated Ia; $\bar{O}_{i}$ is the average of the statistical calculated Ia; and $n$ is the total number of calculated values.

\section{c. HEC-HMS model}

The HEC-HMS model, developed by U.S. Army Corps of Engineers, is a physically based and conceptual semidistributed hydrological model. In each subbasin, the parameters should be calibrated according to the land surface conditions and then the rainfall-runoff process could be simulated. The HEC-HMS distributed hydrological model is composed of four main parts: basin model, meteorological model, control specifications and time series model. The rainfall-runoff process could be obtained through four modules: loss, transformation, routing, and baseflow.

\section{1) Model Setup}

Based on differences in topography and river network shape, the Zijingguan watershed and the Wulongji watershed was divided into 11 subbasins and 29 subbasins adopting HEC-GeoHMS, respectively. The average rainfall of the watershed was estimated using the Thiessen polygon method.

The HEC-HMS model includes 11 loss estimation methods, 7 rainfall-runoff transformation methods, 6 routing methods, and 5 baseflow methods, from which the SCS-CN, SCS unit hydrograph, Muskingum, and recession methods were selected, respectively.

$\mathrm{CN}$ is a comprehensive parameter reflecting the characteristics of the watershed before rainfall and is related to the antecedent moisture condition (AMC), slope, vegetation, soil type, land use and land cover of the watershed. Theoretically, the value of $\mathrm{CN}$ ranges between 0 and 100 . Based on the AMC classes, soil type, and land use and land cover of the study area, we determined the initial value of CN using the National Engineering Handbook (1972).

Lag time is the only parameter to be determined for the SCS unit hydrograph method. Using the average basin slope, the longest flow path and initial $\mathrm{CN}$ value, the initial value of lag time can be acquired. The parameters of Muskingum $K$ and $X$ in the routing module and the recession constant in the baseflow module were determined during the calibration process.

As for Ia, three different sets of values estimated by different methods were employed to run the HEC-HMS model in this paper. In scenario one, the fixed median value of $\mathrm{Ia} / S$, determined by analyzing rainfall-runoff events in the study area, is taken as the HEC-HMS model input. The median value of $\mathrm{I} / S$ is normally adopted as a representative value for the study area in hydrological models (Shi et al. 2009; Fu et al. 2011). Scenario two utilizes the ANN-estimated Ia, which was extracted from the GLDAS datasets and considered the antecedent watershed conditions. For scenario three, HEC-HMS model flood simulations with statistical Ia were carried out. Given that the statistical Ia is obtained from the hydrograph analysis of each flood event, the statistical Ia is considered to be the approximate true value of Ia. Under these circumstances, for parameter Ia, no calibration process is carried out, as Ia is estimated for each flood event based on the hydrograph analysis or the proposed ANN model. Note that other parameters of the HEC-HMS model were calibrated and validated under scenario one to demonstrate the reliability of the model. Specifically, eight events in the Zijingguan watershed were applied for calibration, and six events were employed for validation. In the Wulongji watershed, the number of events for performing calibration and validation was six and four, respectively. After fixing the optimal calibrated parameters of $\mathrm{CN}$, lag time, Muskingum $K, X$ and recession constant in the HEC-HMS model, the value of Ia was adjusted to another corresponding two scenarios to reveal the effects of the variable Ia values on flood simulation. Comparisons between these three scenarios were performed based on the simulation results of flood events.

\section{2) SENSitivity ANALYSIS}

To verify whether Ia is one of the sensitivity parameters in the HEC-HMS model, the modified Morris screening 


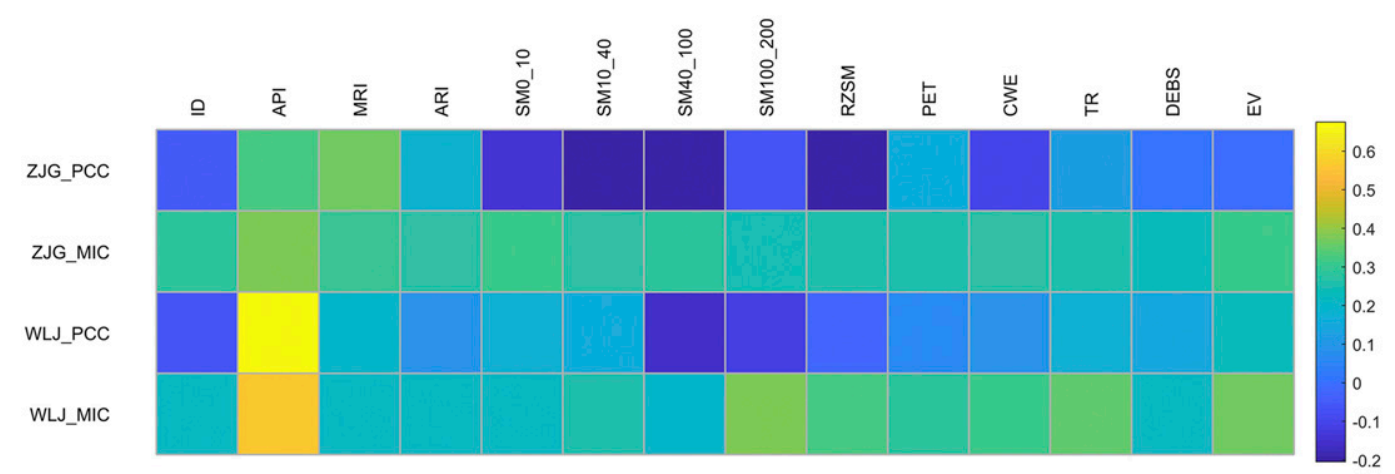

FIG. 7. PCC and MIC values between Ia and 14 potential driving factors (abbreviations: ZJG, Zijingguan watershed; WLJ, Wulongji watershed).

(MMS) method was applied to conduct the sensitivity analysis for the HEC-HMS model. The MMS method provides sensitivity estimation of the entire influence of one parameter on the output and the total measure of sensitivity between parameters ( $\mathrm{Li}$ et al. 2016). One of the parameter values varies while all others remain fixed, and the average change percentage is the sensitivity of this parameter. The formula is shown in Eq. (19):

$$
S_{e}=\sum_{i=1}^{n} \frac{\left(Y_{i+1}-Y_{i}\right) / Y_{i}}{\left(P_{i+1}-P_{i}\right) / P_{i}} \mid n
$$

where $S_{e}$ denotes the sensitivity of each parameter; $Y_{i}$ is the output value of the $i$ th runtime of the model; $Y_{i+1}$ is output value of the $i+1$ th runtime of the model; $P_{i}$ and $P_{i+1}$ represent the change percentage of the operation parameter value relative to the initial parameter for the $i$ th and $i+1$ th model run, respectively; and $n$ is the total runtime of the model. The sensitivity of parameters can be divided into four categories based on the value of $S_{e}$ (Li et al. 2019), that is, $\left|S_{e}\right| \geq 1$ represents the highly sensitive parameter, $0.2 \leq\left|S_{e}\right|<1$ is the sensitive parameter, $0.05 \leq\left|S_{e}\right|<0.2$ denotes the moderately sensitive parameter, and $0 \leq\left|S_{e}\right|<0.05$ indicates that the parameter is insensitive.

\section{Results}

\section{a. Statistical values of Ia and its driving factors}

\section{1) IA/S FOR RAINFALL-RUNOFF EVENTS}

The results illustrated that $\mathrm{Ia} / S$ varies from different events and different watersheds. The calculated Ia/S for 50 rainfall-runoff events in the Zijingguan watershed ranges from 0.001 to 0.48 , with an average value of 0.12 and a median of 0.046 . For the Wulongji watershed, the average value of $\mathrm{Ia} / \mathrm{S}$ is 0.058 , with a median of 0.015 .
Over $75 \%$ of the Ia $/ S$ values are less than 0.2 . Therefore, the results indicated that the traditional $\mathrm{Ia} / S$ value of 0.2 is overestimated in these two study areas. In this study, the median value of Ia/ $S$, namely, 0.046 and 0.015 for the Zijingguan and the Wulongji watershed, respectively, were taken as the representative value, that is, the input value of Ia in the HEC-HMS model under scenario one.

\section{2) IDENTIFICATION OF FACTORS AFFECTING IA}

The PCC and MIC values between the Ia and its potential driving factors (listed in Table 1) were calculated for the two study areas, as shown in Fig. 7. The results presented that the degree of correlation between each factor and Ia varies greatly from different methods and watersheds. An absolute value of the PCC below 0.2 is considered to be a weak correlation. The MIC values of all the factors are above 0.2. It is obvious that there is a strong correlation between Ia and some potential factors, such as API, MRI and ARI. To identify the most significant driving factors, AHP was adopted to sort the potential factors to train the optimal ANN model, as shown in Table 2.

Based on the order of each factor, different cases were designed, and then the ANN model was computed for different cases with different input factors. Case 1 consists of the first five high correlation factors of Ia, and the new factor was added in turn to the new cases according to the AHP results. Consequently, total 10 cases were designed to train the ANN model. By evaluating the performance, the most significant factors influencing Ia were determined. The evaluations of different cases in ANN model are listed in Table 3.

Overall, it can be seen that the evaluation of the ANN model training process outperformed that of the validation process in most cases. Intuitively, case 8 in the Zijingguan watershed, which is composed of API, MRI, SM0_10, SM40_100, RZSM, SM10_40, EV, ARI, ID, PET, CWE, and TR (a total of 12 factors), is considered 
TABLE 2. The AHP weights of 14 potential driving factors for the two watersheds.

\begin{tabular}{clcccllc}
\hline \hline \multicolumn{3}{c}{ Zijingguan watershed } & & \multicolumn{3}{c}{ Wulongji watershed } \\
\cline { 1 - 3 } \cline { 7 - 8 } Order & Factors & Weights & & Order & Factors & Weights \\
\hline 1 & API & 0.1927 & & 1 & API & 0.2159 \\
2 & MRI & 0.1596 & & 2 & EV & 0.1508 \\
3 & SM0_10 & 0.1049 & & 3 & TR & 0.1033 \\
4 & SM40_100 & 0.0814 & & 4 & SM100_200 & 0.1009 \\
5 & RZSM & 0.0769 & & 5 & MRI & 0.0823 \\
6 & SM10_40 & 0.0767 & & 6 & SM0_10 & 0.0515 \\
7 & EV & 0.0764 & & 7 & RZSM & 0.0510 \\
8 & ARI & 0.0480 & & 8 & SM10_40 & 0.0452 \\
9 & ID & 0.0426 & & 9 & CWE & 0.0451 \\
10 & PET & 0.0383 & & 10 & SM40_100 & 0.0421 \\
11 & CWE & 0.0334 & & 11 & PET & 0.0358 \\
12 & TR & 0.0279 & & 12 & DEBS & 0.0318 \\
13 & SM100_200 & 0.0213 & & 13 & ARI & 0.0250 \\
14 & DEBS & 0.0200 & & 14 & ID & 0.0193 \\
\hline
\end{tabular}

to be the best fitness. For the Wulongji watershed, case 4 including API, EV, TR, SM100_200, MRI, SM0_10, RZSM, and SM10_40 (a total of 8 factors), is the optimal combination.

\section{b. ANN estimation results of Ia}

Taking the Zijingguan watershed as an example, Fig. 8a illustrates the performance plots of the ANN model in training and validation process under the best fitness case 8 for four statistical indicators. It is clear that when epochs are equal to 55, four statistical indicators provide the best fitness. Otherwise, an overfitting problem arises, that is, the evaluation results on the validation process become worse. Accordingly, during the test process, we set epochs equal to 55 .

The correlation plot of the statistical Ia and the ANN-estimated Ia for flood events in the two watersheds (Fig. 8b) demonstrates that scattered points are evenly distributed on both sides of the trend line. The correlation coefficient (CR) between statistical Ia and ANN-estimated Ia is more than 0.7 in the two study areas, and the coefficient of determination $\left(R^{2}\right)$ exceeds 0.6 , reaching 0.83 in the Zijingguan watershed, which indicates that although ANN model underestimates or overestimates in some cases, ANN model could capture the relationship between statistical Ia and estimated Ia in general.

\section{c. Land use and land cover change analysis}

Five categories were made for LULC maps, namely, water, forest, agricultural land, grassland, and urban areas. Change analysis was performed by calculating the areas of different land cover types in 1980 for the Zijingguan watershed (1992 for the Wulongji watershed) and its corresponding areas in 2015 for the Zijingguan

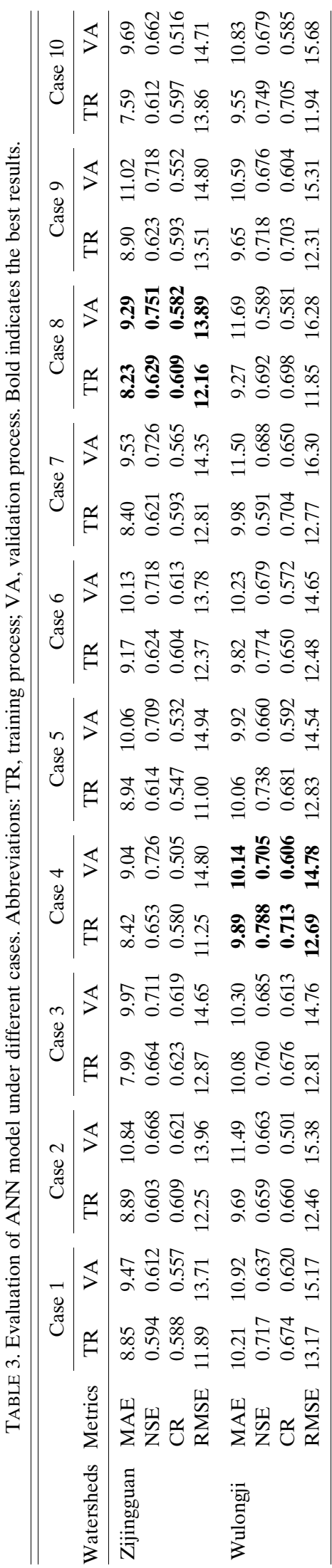



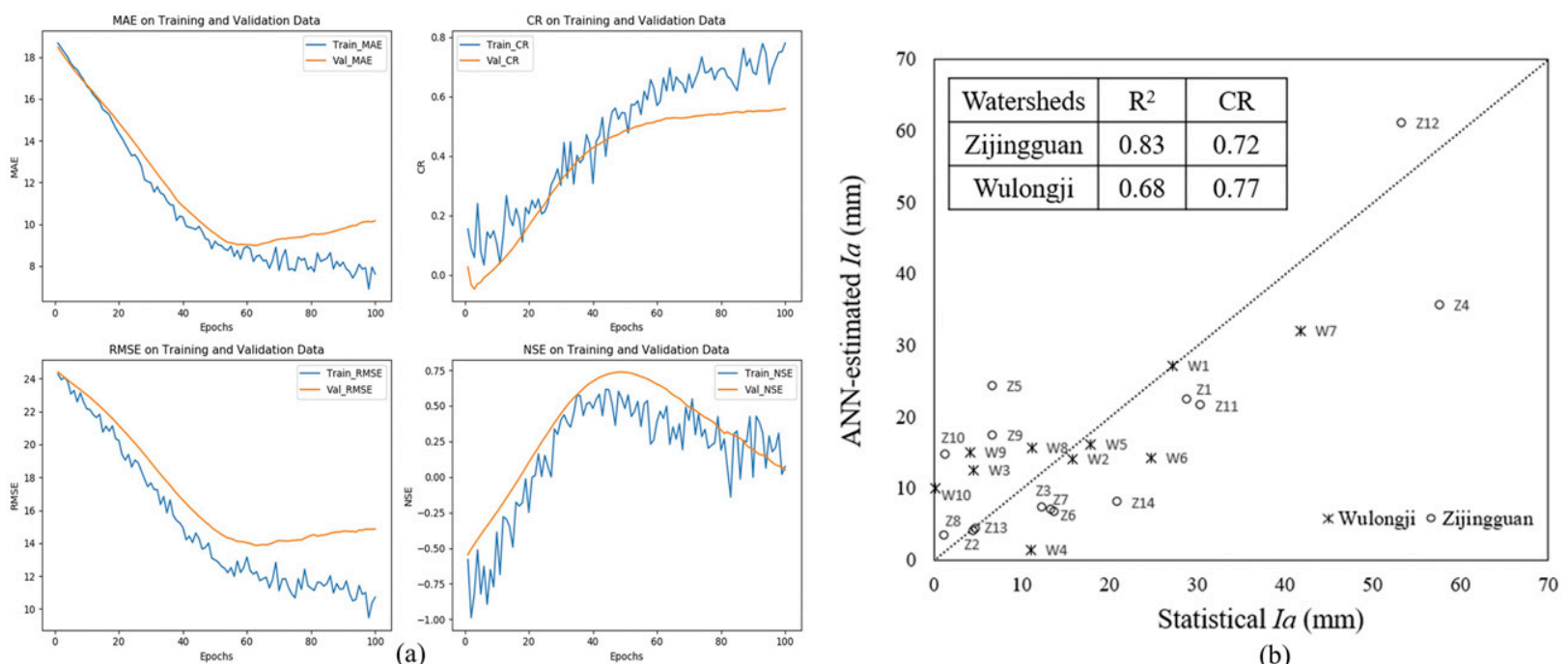

(b)

FIG. 8. ANN estimation of Ia. (a) Performance plots of ANN model in training and validation process under the best fitness case 8 for four statistics indicators in the Zijingguan watershed; (b) correlation plot of the statistical Ia and the ANN-estimated Ia for the two study areas.

watershed (2014 for the Wulongji watershed), as shown in Fig. 9.

For the Zijingguan watershed, there was an increase in forest and urban areas, followed by a decrease in agricultural land and grassland during 1980-2015. However, the water area basically remained unchanged. The largest change in LULC in the Zijingguan watershed was concentrated on the conversion between forest and grassland. $\mathrm{Li}$ and Feng (2011) simulated the impact of the change in LULC on floods in the Zijingguan watershed during 1980-2000. The results indicated that the mutual transformation among the three land use types of agricultural land, forest and grassland would not cause dramatic changes in flood peak and flood volume.

In this study, a total of 14 flood events in the Zijingguan watershed were selected to explore the effect of LULC change on discharge. The $\mathrm{CN}$ values in the HEC-HMS model for 1980 and 2015 land use conditions were determined according to the LULC and the soil type, and the other parameters remained unchanged. The flood simulation results, as shown in Table 4, indicated that the flood peak and depth decreased slightly, with a reduction percentage of $<3 \%$, as forest cover increased from 1980 to 2015 . The effects of LULC change were relatively small for large flood events $(T>10 \mathrm{yr})$, with a percentage of approximately $1 \%$, which is consistent with the results of numerous studies (Bathurst et al. 2011; Birkinshaw et al. 2010; Bathurst et al. 2016).

Additionally, the variation in $\mathrm{CN}$ values for the whole watershed under two different LULC scenarios was analyzed, and the values fluctuated from 59.3 to
58.4 during the period of 1980-2015. As a result, the flood slightly decreased due to the decrease in $\mathrm{CN}$ values. The possible reason lies in that the LULC of the Zijingguan watershed was mainly concentrated in the conversion between forest and grassland according to the LULC analysis. However, the $\mathrm{CN}$ values of these two land use types are similar. In the NEH-4 table (SCS 1956), the CN values for forest are slightly lower than those for grassland. Thus, the increase in forest and decrease in grassland led to a decrease in $\mathrm{CN}$ values. Although the urban area, regarded as the primary factor leading to the significant change in flood peak and volume (Sanyal et al. 2014; Younis and Ammar 2018; Koneti et al. 2018), expanded, the $\mathrm{CN}$ values of the whole watershed still decreased.

In addition to the area of land use change, there are other factors affecting flood generation. Bathurst et al. (2016) illustrated that the extent to which changes in forest cover can alter flood peak discharges depends on the proportion of the catchment affected and on the location of the change in the catchment. Generally, the change in forest cover must apply to $20 \%-30 \%$ of the catchment area to affect the hydrological response. In some cases, the effects of forest cover change would become attenuated on a larger scale due to nonuniform rainfall or a greater heterogeneity of land use (Birkinshaw et al. 2010). Additionally, most of the selected floods in the Zijingguan watershed occurred before 1995, so the effect of LULC on discharge was even less obvious.

For the Wulongji watershed, it can be found that there was a slight increase in grassland, urban areas and water area from 1992 to 2014, while the area of agricultural 

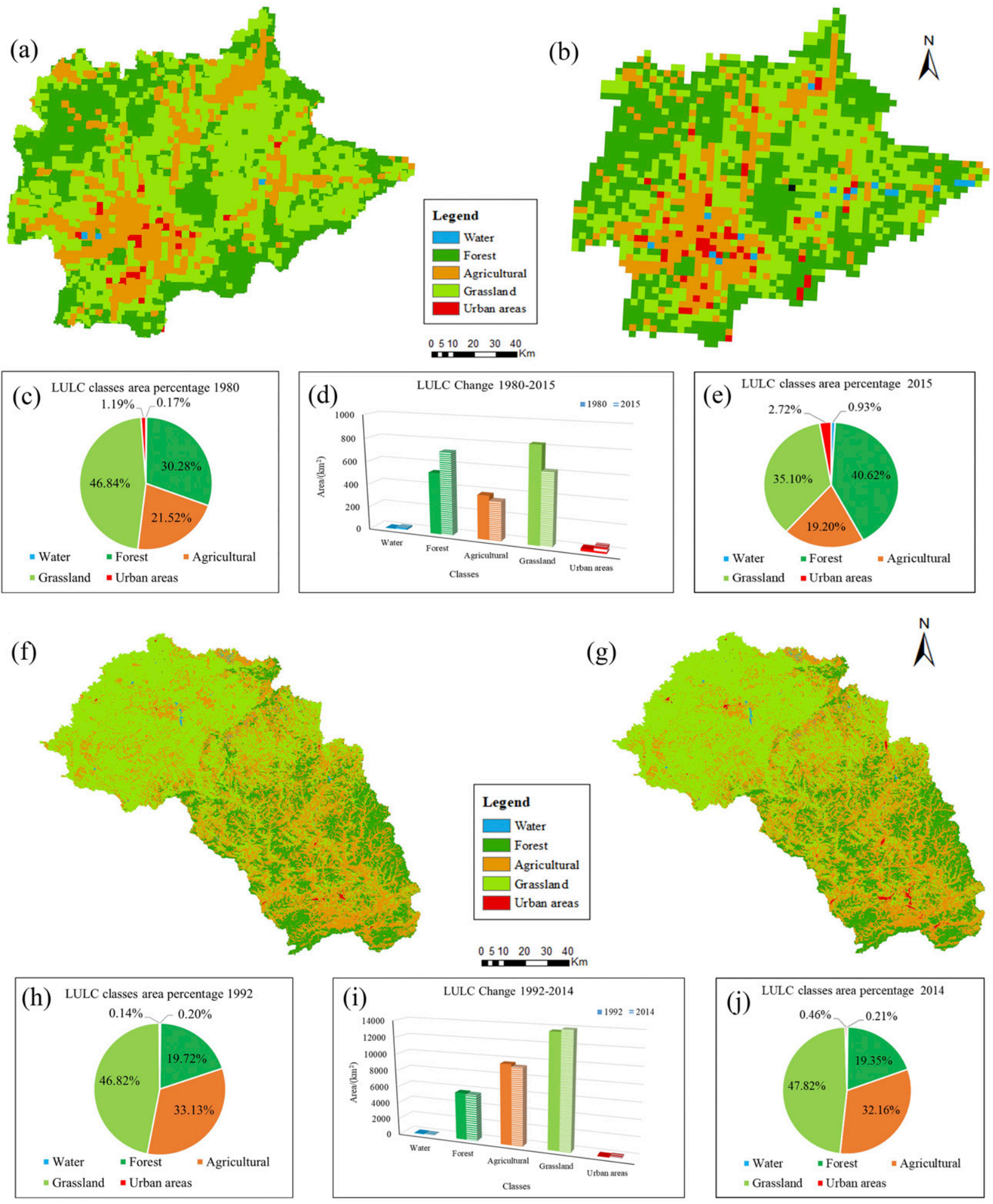

FIG. 9. LULC change analysis for the two study areas. LULC map for the Zijingguan watershed in (a) 1980 and (b) 2015, and its corresponding LULC classes area percentage pie chart of (c) 1980 and (e) 2015; LULC map for the Wulongji watershed in (f) 1992 and (g) 2014, and its corresponding LULC classes area percentage pie chart of (h) 1992 and (j) 2014; (d) LULC change during 1980-2015 in the Zijingguan watershed; (i) LULC change during 1992-2014 in the Wulongji watershed. 
TABLE 4. Comparison of the percentage change in discharge values for the Zijingguan watershed under two different LULC scenarios.

\begin{tabular}{|c|c|c|c|c|c|c|c|}
\hline \multirow[b]{2}{*}{ Flood magnitude } & \multirow[b]{2}{*}{ Event } & \multicolumn{3}{|c|}{ Flood peak $\left(\mathrm{m}^{3} \mathrm{~s}^{-1}\right)$} & \multicolumn{3}{|c|}{ Flood depth $(\mathrm{mm})$} \\
\hline & & 1980LULC & 2015LULC & Percentage change & 1980LULC & 2015LULC & Percentage change \\
\hline \multirow{5}{*}{$T<10 \mathrm{yr}$} & E6 & 263 & 256 & $-2.60 \%$ & 17.69 & 17.25 & $-2.50 \%$ \\
\hline & E7 & 156 & 154 & $-1.26 \%$ & 4.54 & 4.46 & $-1.82 \%$ \\
\hline & E9 & 263 & 257 & $-2.12 \%$ & 25.75 & 25.21 & $-2.09 \%$ \\
\hline & E11 & 127 & 125 & $-1.66 \%$ & 5.64 & 5.53 & $-1.94 \%$ \\
\hline & E12 & 120 & 118 & $-1.25 \%$ & 2.84 & 2.76 & $-2.82 \%$ \\
\hline \multirow[t]{6}{*}{$10-20 \mathrm{yr}$} & E2 & 364 & 358 & $-1.66 \%$ & 18.91 & 18.63 & $-1.50 \%$ \\
\hline & E3 & 555 & 550 & $-0.94 \%$ & 75.38 & 74.51 & $-1.15 \%$ \\
\hline & E5 & 771 & 759 & $-1.57 \%$ & 65.05 & 64.19 & $-1.32 \%$ \\
\hline & E8 & 460 & 453 & $-1.37 \%$ & 29.01 & 28.6 & $-1.42 \%$ \\
\hline & E10 & 437 & 432 & $-1.19 \%$ & 28.28 & 27.83 & $-1.61 \%$ \\
\hline & E13 & 704 & 693 & $-1.56 \%$ & 71.58 & 70.46 & $-1.56 \%$ \\
\hline \multirow[t]{3}{*}{$T>20 \mathrm{yr}$} & E1 & 1393 & 1383 & $-0.73 \%$ & 140.02 & 138.89 & $-0.81 \%$ \\
\hline & E14 & 2079 & 2069 & $-0.45 \%$ & 46.12 & 45.72 & $-0.87 \%$ \\
\hline & E4 & 3623 & 3609 & $-0.37 \%$ & 289.60 & 287.77 & $-0.63 \%$ \\
\hline
\end{tabular}

land and forest decreased. All the change percentages are within $1 \%$. Thus, the LULC change in the Zijingguan and Wulongji watersheds had a small impact on the flood simulation. In this study, the LULC maps and soil maps of 1995 were used to generate $\mathrm{CN}$ values as the initial input and then calibrated to obtain the optimal CN in HEC-HMS model.

\section{d. Sensitivity analysis of the HEC-HMS model}

Given that the model structure is determined, sensitivity analysis was only performed for two flood events occurring in 1963 and 1975 in the Zijingguan watershed to test the influence of flood magnitude on Ia. The maximum peak discharge in 1963 and 1975 were 4490 and $139 \mathrm{~m}^{3} \mathrm{~s}^{-1}$, respectively, which represents floods of different magnitudes. The sensitivity of six parameters for the HEC-HMS model was calculated using the MMS method. The value of the parameters varied from the optimal value to $50 \%$ of the optimal value with an increment step of $10 \%$. The impacts of the six parameters on flood peak, flood depth, and flood peak appearance time were studied.

The results illustrated that the sensitivity of parameters differed for different flood characteristics and different flood magnitudes. With respect to the flood peak of the 1963 flood event, CN was the most sensitive parameter, followed by Muskingum $K$ and Ia. For the flood depth of the 1963 flood event, Ia was the second most sensitive parameter, following $\mathrm{CN}$. Ia had no impact on the flood peak appearance time of the 1963 flood event, and the most significant parameter was lag time. With respect to the flood peak and flood depth of the 1975 flood event, Ia ranked second, following $\mathrm{CN}$. In addition, Ia affected the flood peak appearance time of the 1975 flood event.
The results indicated that Ia was basically the most sensitive parameter, except for $\mathrm{CN}$, in flood events of different magnitudes. Moreover, Ia had a higher impact on flood events of lesser magnitude.

\section{e. Comparison of the HEC-HMS model under three scenarios}

The HEC-HMS model was computed under three scenarios. Scenario one computes the HEC-HMS model with the fixed median value of $\mathrm{Ia} / S$, which is obtained by statistical analysis of rainfall-runoff events. The second scenario takes ANN-estimated Ia as the HEC-HMS model parameters, whereas the third scenario applies statistical Ia as the HEC-HMS model input. The simulations of the HEC-HMS model under these three scenarios are shown in Fig. 10. The performance of the HEC-HMS model under three scenarios are evaluated with NSE and the relative error (RE) of flood peak and flood depth, as listed in Table 5.

From Fig. 10, it can be clearly observed that there is a dramatic deviation between the observed hydrograph and the simulated hydrograph when statistical median $\mathrm{Ia} / S$ is adopted for flood events $1,2,7,9$, and 14 in the Zijingguan watershed, and flood events 1, 2, 3, 4, 7, and 8 in the Wulongji watershed. The RE of flood peak or flood depth for these flood events exceeds $20 \%$, which fails to meet the accuracy requirement.

In contrast, in more than half of the flood simulation results, employing statistical Ia as the HEC-HMS model input gives satisfactory results. For total 24 flood events in the two study areas, the number of flood events with the smallest RE of flood peak, flood depth and the best NSE accounts for $50 \%$ under this scenario. Hence, the simulation under scenario three is proved more reliable in accurate prediction of flood discharge. 


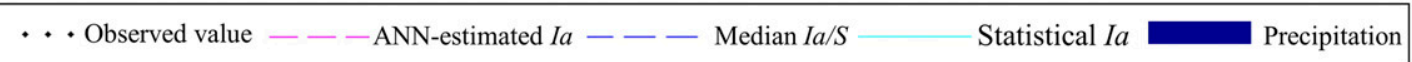
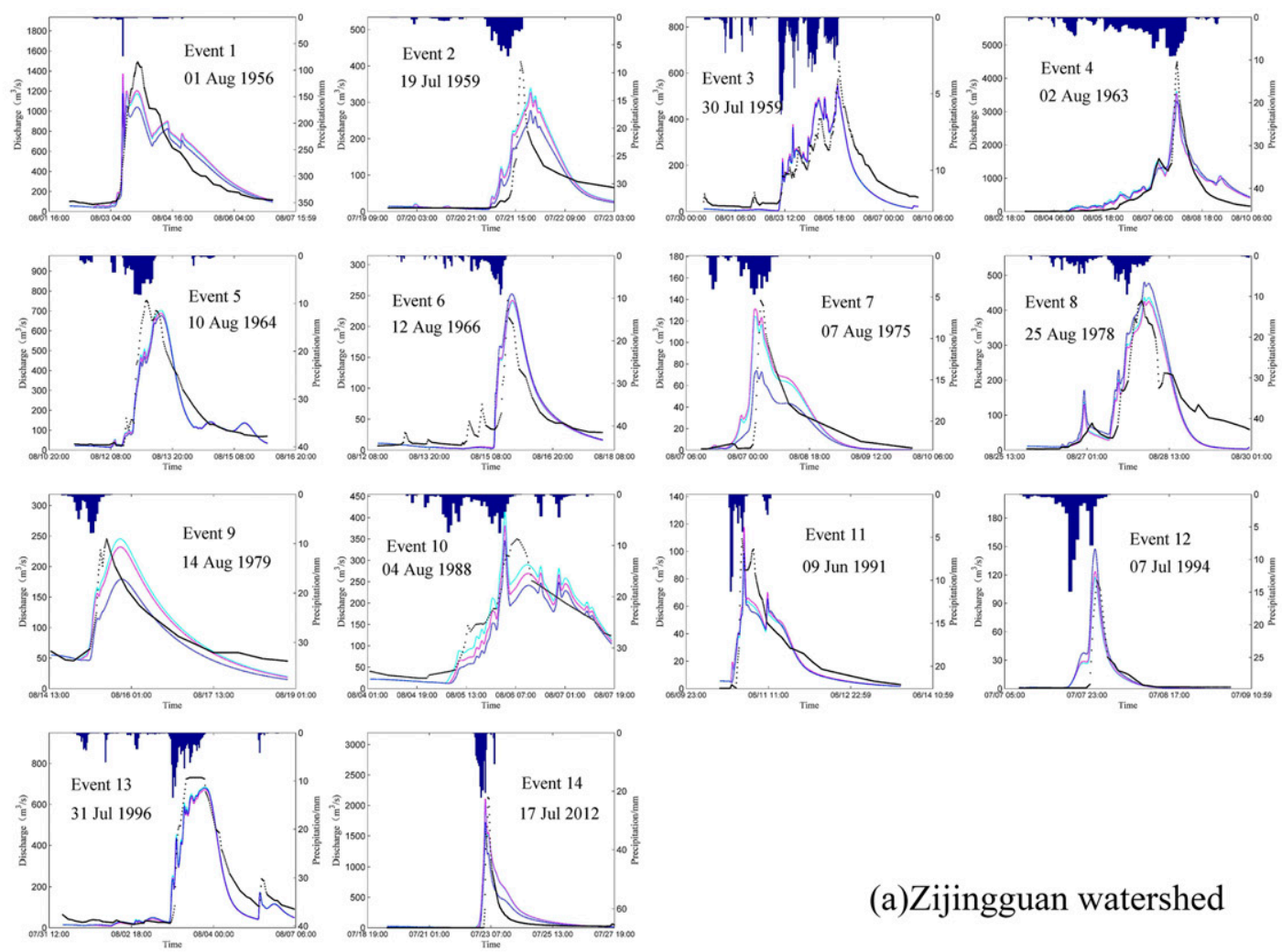

(a)Zijingguan watershed
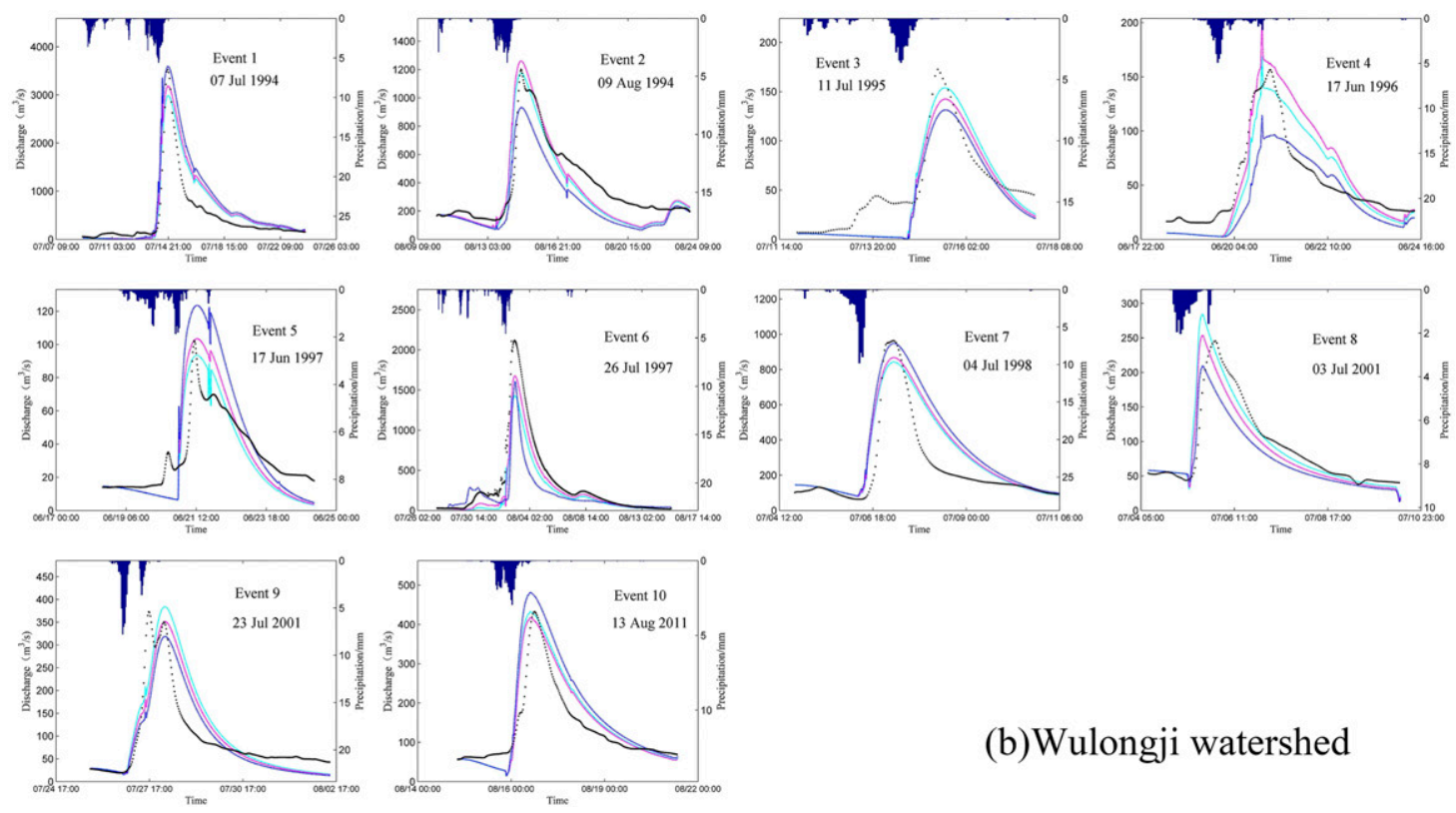

(b)Wulongji watershed

FIG. 10. Observed and simulated hydrographs for total 24 flood events with ANN-estimated Ia, statistical Ia, and the median $\mathrm{Ia} / S$ at calibration, validation stage in the two study areas (a) Zijingguan watershed and (b) Wulongji watershed. 


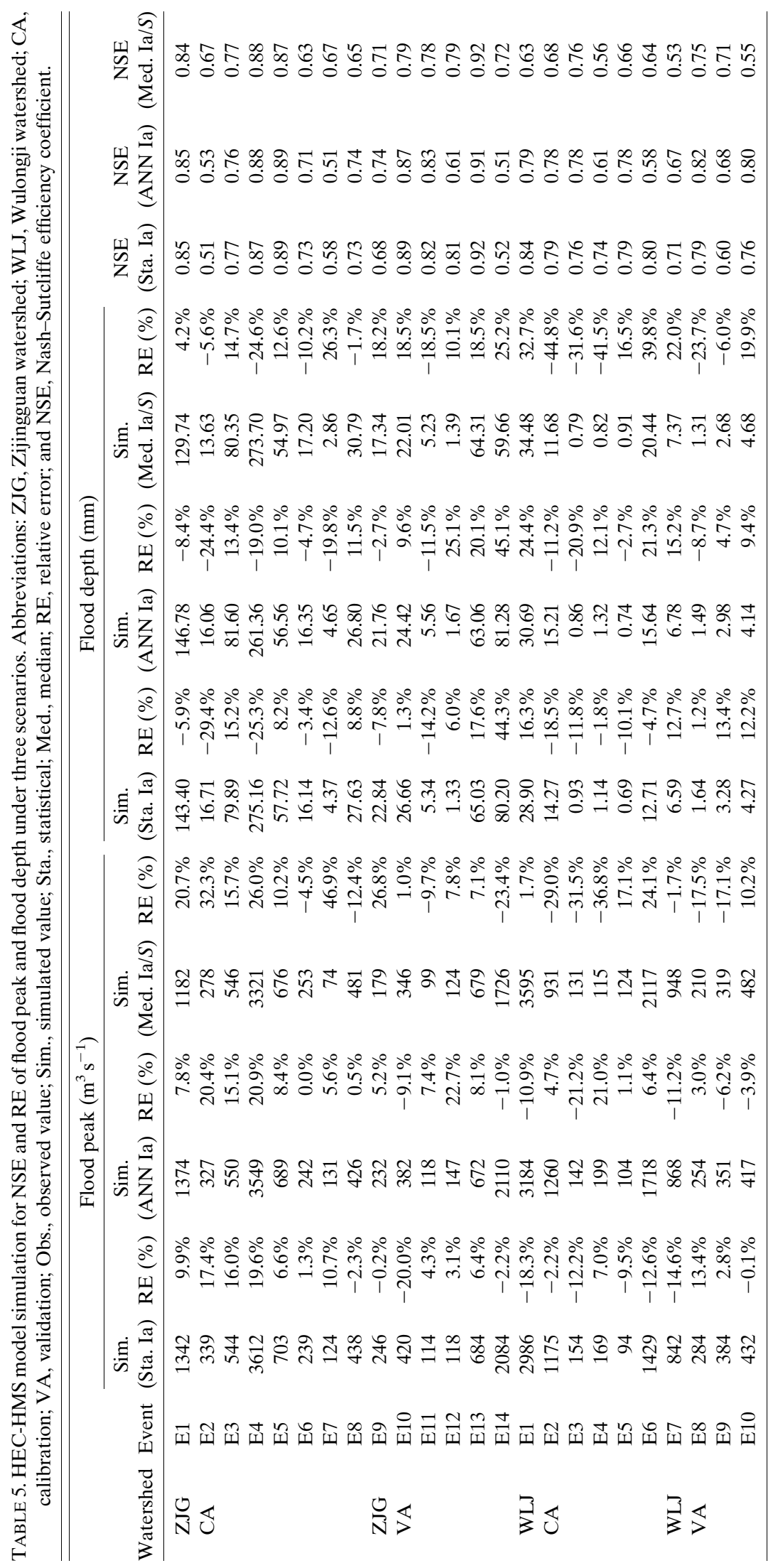


Meanwhile, the results indicate that the number of flood events simulation under scenario two with the smaller RE of flood peak, flood depth and better NSE is twice of that of scenario one. Accordingly, the HEC-HMS model built with ANN-estimated Ia outperforms the median $\mathrm{Ia} / S$ value. Over $60 \%$ of flood events, the RE of flood peak and flood depth simulated by ANN-estimated Ia are smaller than those of the scenario one. Furthermore, NSE and RE of flood peak and flood depth of five flood events in the Zijingguan watershed (events 4, 5, 6, 9, 11) and six flood events in the Wulongji watershed (events 2, 3, 4, $5,8,10)$ under scenario two demonstrates better fitness than scenario one. Additionally, as shown in Table 5, the average RE of flood peak and flood depth for total 24 flood events under three scenarios are $8.9 \%$ (statistical Ia), 9.2\% (ANN-estimated Ia), 18.0\% (median $\mathrm{Ia} / S$ ), and $12.6 \%, 14.8 \%, 20.3 \%$, respectively. In particular, the average RE of flood peak with median $\mathrm{Ia} / S$ is almost twice of that of ANN-estimated Ia, and a deviation of approximately $10 \%$ can be found for the average RE of flood depth between these two scenarios. In contrast, the difference between statistical Ia and ANN-estimated Ia for the average RE of flood peak and flood depth is all within $2.2 \%$.

Consequently, compared with the median $\mathrm{Ia} / S$ as input, the error of flood peak and flood depth between the observed and simulated values can be reduced with ANN-estimated Ia in the HEC-HMS model. Although the ANN model underestimates the statistical Ia of flood event 4 (2 August 1963) in the Zijingguan watershed, the flood event with large magnitude is not sensitive to Ia. Therefore, the accuracy of flood simulation from flood event 4 (2 August 1963) is not affected.

\section{Discussion}

Ia is a sensitive parameter in hydrological models and is difficult to obtain due to a lack of observed data. Given that the watershed antecedent wetness conditions and rainfall characteristics are diverse for each flood event, Ia varies from different flood events. Consequently, in the event-based hydrological model, Ia must be calibrated for each event. However, for every flood event, the calibration of model parameters to find a set of parameters that make simulated flood events fit the observed flood events well is time consuming. Moreover, the optimal parameters, which are explored during the automatic calibration process, often lose their physical significance.

Several studies have revealed that the adjustment of $\mathrm{Ia} / S$ to 0.05 from the traditional value of 0.20 in the SCS-CN method can produce better estimates of runoff
(Hawkins et al. 2002; Shi et al. 2009; Fu et al. 2011; Noori et al. 2012; Hawkins et al. 2019). Noori et al. (2012) have also obtained superior results with $\mathrm{Ia} / S=0.05$ in a study exploring the effect of the variation of Ia/ $S$ on simulating urbanization impacts with the HEC-HMS model. Hence, in this paper, taking the temporal variations of Ia into consideration, the factors influencing Ia are extracted from observed rainfall-runoff events and GLDAS datasets to estimate Ia for each flood event. A hydrological model is constructed with varying Ia parameters for each flood event, depending on antecedent wetness conditions and rainfall characteristics. In addition, the calibration of model parameters for Ia can be omitted, which saves time and effort.

In the proposed Ia-estimation method, great significance should be attached to the prediction accuracy of the ANN model. Since the two study areas are in subhumid and semiarid area, there is not enough rainfall in the flood season. Consequently, insufficient rainfallrunoff events data were collected to build the ANN model, which might affect the accuracy of Ia estimation. However, despite that ANN model underestimates or overestimates Ia in some cases, it brings about little influence on the results of flood simulation. The most possible reason lies in that the sensitivity of Ia in the HEC-HMS model varies from different flood events. For instance, the flood event with large magnitude is not sensitive to Ia. In general, the accuracy of hydrological model simulation applying ANN-estimated Ia can meet the requirements.

The dominant driving factors affecting Ia vary from different river basins, while the antecedent precipitation index (API) is the most influential factor on Ia in general. Maximum rainfall intensity (MRI) also greatly affects Ia, both ranking among the top five influencing factors of Ia in these two watersheds. For the Zijingguan watershed, the API, MRI, ARI, and soil moisture ranging from 0 to $100 \mathrm{~cm}$ are the most important factors affecting Ia, which proves that rainfall characteristics and surface soil moisture are crucial to Ia for small watersheds. Nevertheless, in the Wulongji watershed, evapotranspiration lists among the top three potential driving factors of Ia.

The possible reason is that the dominant driving factors of Ia in different watersheds may be related to the watershed characteristics as well as rainfall properties. The Zijingguan watershed is located in the mountain area of the Daqing River basin, with an average watershed slope reaching $27.2 \%$, which is almost 1.5 times that of the Wulongji watershed. In addition, the average MRI value for a total of 64 rainfall-runoff events in the Zijingguan watershed was $9.2 \mathrm{~mm} \mathrm{~h}^{-1}$, which was more than twice that of the Wulongji watershed. 
Consequently, the flood in the Zijingguan watershed rises rapidly due to the high rainfall intensity and the high basin slope. As a result, according to the definition of Ia, the duration of the beginning of rainfall to the start of runoff generation, namely, the Ia generation time, is relatively short in the Zijingguan watershed. Through statistical analysis from all selected rainfall-runoff events for the two watersheds, the Ia generation duration was only $10.2 \mathrm{~h}$ in the Zijingguan watershed, which was one-fifth of that in the Wulongji watershed. In this paper, evapotranspiration data are extracted only during the Ia generation duration for Ia impact analysis. Therefore, in this short Ia generation duration for the Zijingguan watershed, evapotranspiration may have little effect on Ia, while rainfall intensity is the dominant factor in the smallerscale watershed. In contrast, for the Wulongii watershed, the effect of evapotranspiration on Ia cannot be neglected in the duration of Ia generation. Accordingly, to predict Ia more accurately, the identification of the potential driving factors affecting Ia is also significant.

The biggest superiority of ANN model is that as long as there is sufficient rainfall-runoff data to train ANN in a given river basin, the predicted Ia can be obtained based on the antecedent watershed conditions of each flood event, so as to provide a more reliable and physically based Ia value for the construction of watershed hydrological model. In future, the spatial characteristics of antecedent wetness conditions in the subbasins should be considered to improve the accuracy of Ia estimation for the hydrological model. Furthermore, the proposed ANN estimation method only applied in two study areas, a small watershed with $1760 \mathrm{~km}^{2}$ and a large watershed with $30100 \mathrm{~km}^{2}$, more verification should be performed on the basis of sufficient available data in more river basins around world in the near future.

\section{Conclusions}

This paper investigates the potential of soil moisture and evaporation data from GLDAS-Noah datasets for estimating Ia. The motivation of the study was to propose the new Ia estimation methods for hydrological models and prove its feasibility. The main conclusions of this paper are drawn as follows.

1) $\mathrm{Ia} / S$ varies from different events and different watersheds. For the 50 rainfall-runoff events over the period from 1956 to 2014 in the Zijingguan watershed, Ia/S ranges from 0.001 to 0.48 , with an average value of 0.12 and a median of 0.046 . For the Wulongij watersheds, the average value of $\mathrm{Ia} / S$ is 0.058 , with a median of 0.015 . Over $75 \%$ of the Ia/ $S$ values are less than 0.2 in the two study areas.
2) The driving factors affecting Ia are different in the two watersheds. Noticeably, antecedent precipitation index (API) is the most significant factor of Ia. Rainfall characteristics and surface soil moisture in small watershed are the main factors of Ia, while evaporation in large watershed cannot be ignored.

3) Among the three scenarios, employing statistical Ia as the HEC-HMS model input demonstrates the best performance, where the simulated flood peak and flood depth fitted the observed well. Although the derivation between simulated hydrograph with ANN-estimated Ia and observed hydrograph can be found in the modeling results, the HEC-HMS model built with ANN-estimated Ia outperforms the tradition methods, namely, the median value of Ia $/ S$. Over $60 \%$ of flood events in two study areas, both the RE of flood peak and flood depth simulated by ANN-estimated Ia performed better than those of applying median $\mathrm{Ia} / S$ in the HEC-HMS model. The proposed Ia estimation method can meet accuracy requirements and reduce parameter calibration work in hydrological modeling.

Ia for each flood event is derived using the ANN estimation method proposed in this paper and serves as the input parameter in the hydrological model. The temporal variations of soil moisture, evaporation and other antecedent conditions of the watershed are taken into account, which makes the estimation of Ia physically based. Hence, this method saves time and effort in calibrating parameters in the hydrological model.

Acknowledgments. This research is supported by the National Key Research and Development Program of China (2018YFC0407902) and the National Natural Science Foundation of China (51779165). The authors declare that they have no known competing financial interests or personal relationships that could have appeared to influence the work reported in this paper. GLDAS-Noah v2.0 datasets are available from https:// giovanni.gsfc.nasa.gov/.

\section{REFERENCES}

Arnold, J. G., J. R. Williams, R. Srinivasan, and K. W. King, 1996: The Soil and Water Assessment Tool (SWAT) user's manual. Grassland, Soil and Water Research Laboratory, Agriculture Research Service, USDA, 102 pp.

Bai, S., M. Li, R. Kong, S. Han, H. Li, and L. Qin, 2019: Data mining approach to construction productivity prediction for cutter suction dredgers. Autom. Constr., 105, 102833, https:// doi.org/10.1016/j.autcon.2019.102833.

Balkhair, K. S., and Coauthors, 2018: Groundwater share quantification through flood hydrographs simulation using two temporal rainfall distributions. Desalin. Water Treat., 114, 109-119, https://doi.org/10.5004/dwt.2018.22346. 
Baltas, E. A., N. A. Dervos, and M. A. Mimikou, 2007: Determination of the SCS initial abstraction ratio in an experimental watershed in Greece. Hydrol. Earth Syst. Sci., 11, 1825-1829, https://doi.org/ 10.5194/hess-11-1825-2007.

Bathurst, J. C., and Coauthors, 2011: Forest impact on floods due to extreme rainfall and snowmelt in four Latin American environments 1: Field data analysis. J. Hydrol., 400, 281-291, https://doi.org/10.1016/j.jhydrol.2010.11.044.

— - S. J. Birkinshaw, F. Cisneros Espinosa, and A. Iroumé, 2016: Forest impact on flood peak discharge and sediment yield in streamflow. River Syst. Anal. Manage., 15-29, https://doi.org/ 10.1007/978-981-10-1472-7_2.

Beaudoing, H. K., M. Rodell, and NASA/GSFC/HSL, 2015: GLDAS Noah land surface model L4 3 hourly $0.25 \times 0.25$ degree V2.0. Goddard Earth Sciences Data and Information Services Center (GES DISC), accessed 24 April 2019, https:// doi.org/10.5067/342OHQM9AK6Q.

Bhuiyan, H. A. K. M., H. McNairn, J. Powers, and A. Merzouki, 2017: Application of HEC-HMS in a cold region watershed and use of RADARSAT-2 soil moisture in initializing the model. Hydrology, 4, 9, https://doi.org/10.3390/hydrology4010009.

Birkinshaw, S. J., J. C. Bathurst, A. Iroumé, and H. Palacios, 2010: The effect of forest cover on peak flow and sediment discharge-An integrated field and modelling study in central-southern Chile. Hydrol. Processes, 25, 1284-1297, https://doi.org/10.1002/hyp.7900.

Box, G. E. P., and G. M. Jenkins, 1970: Time Series Analysis: Forecasting and Control. San Francisco: Holden-Day, 537 pp.

Brocca, L., F. Melone, T. Moramarco, and V. P. Singh, 2009: Assimilation of observed soil moisture data in storm rainfallrunoff modeling. J. Hydrol. Eng., 14, 153-165, https://doi.org/ 10.1061/(ASCE)1084-0699(2009)14:2(153).

Chollet, F., 2016: Keras documentation: The Python deep learning library. Accessed 18 April 2018, https://keras.io.

Dunkerley, D., 2008: Identifying individual rain events from pluviograph records: A review with analysis of data from an Australian dryland site. Hydrol. Processes, 22, 5024-5036, https://doi.org/10.1002/hyp.7122.

Dunne, T., 1978: Field studies of hillslope flow processes. Hillslope Hydrology, M. J. Kirkby, Ed., Wiley, 227-293.

Fischer, S., A. Schumann, and M. Schulte, 2016: Characterisation of seasonal flood types according to timescales in mixed probability distributions. J. Hydrol., 539, 38-56, https://doi.org/ 10.1016/j.jhydrol.2016.05.005.

Fu, S., G. Zhang, N. Wang, and L. Luo, 2011: Initial abstraction ratio in the SCS-CN method in the Loess Plateau of China. Trans. ASABE, 54, 163-169, https://doi.org/10.13031/ 2013.36271.

Furey, P. R., and V. K. Gupta, 2005: Effects of excess rainfall on the temporal variability of observed peak-discharge power laws. Adv. Water Resour., 28, 1240-1253, https://doi.org/10.1016/ j.advwatres.2005.03.014.

Green, W. H., and G. A. Ampt, 1911: Studies on soil physics, Part I. The flow of air and water through soils. J. Agric. Sci., 4, 11-24.

Gupta, V. K., I. Rodríguez-Iturbe, and E. F. Wood, 1986: Scale Problems in Hydrology Runoff Generation and Basin Response. Springer, $246 \mathrm{pp}$.

Hawkins, R. H., A. T. Hjelmfelt Jr., and A. W. Zevenbergen, 1985: Runoff probability, storm depth, and curve numbers. J. Irrig. Drain. Eng., 111, 330-340, https://doi.org/10.1061/(ASCE) 0733-9437(1985)111:4(330).

—, R. Jiang, D. E. Woodward, A. T. Hjelmfelt, J. A. Van Mullem, and Q. D. Quan, 2002: Runoff curve number method:
Examination of the initial abstraction ratio. Second Federal Interagency Hydrologic Modeling Conf., Las Vegas, NV, Water Information Coordination Program, $16 \mathrm{pp}$.

—, T. J. Ward, D. E. Woodward, and J. A. Van Mullen, 2009: Curve Number Hydrology-State of the Practice. American Society of Civil Engineers, 106 pp., https://doi.org/10.1061/ 9780784410042.

— F. D. Theurer, and M. Rezaeianzadeh, 2019: Understanding the basis of the curve number method for watershed models and TMDLs. J. Hydrol. Eng., 24, 06019003, https://doi.org/ 10.1061/(ASCE)HE.1943-5584.0001755.

Horton, R. E., 1933: The role of infiltration in the hydrologic cycle. Eos, Trans. Amer. Geophys. Union, 14, 446-460, https:// doi.org/10.1029/TR014i001p00446.

_ 1941: An approach toward a physical interpretation of infiltration-capacity. Soil Sci. Soc. Amer. Proc., 4, 399-417, https:// doi.org/10.2136/SSSAJ1941.036159950005000C0075X.

Hu, C., Q. Wu, H. Li, S. Jian, N. Li, and Z. Lou, 2018: Deep learning with a long short-term memory networks approach for rainfall-runoff simulation. Water, 10, 1543, https://doi.org/ 10.3390/w10111543.

Kashid, S. S., and R. Maity, 2012: Prediction of monthly rainfall on homogeneous monsoon regions of India based on large scale circulation patterns using genetic programming. J. Hydrol., 454-455, 26-41, https://doi.org/10.1016/j.jhydrol.2012.05.033.

Kaur, H., and V. Jothiprakash, 2013: Daily precipitation mapping and forecasting using data driven techniques. Int. J. Hydrol. Sci. Technol., 3, 364-377, https://doi.org/10.1504/IJHST.2013.060337.

Knisel, W. G., Ed., 1980: CREAMS: A Field-Scale Model for Chemical, Runoff and Erosion from Agricultural Management Systems. Conservation Research Report, Vol. 26, Department of Agriculture, Science \& Education Administration, 643 pp.

Koneti, S., S. L. Sunkara, and P. S. Roy, 2018: Hydrological modeling with respect to impact of land-use and land-cover change on the runoff dynamics in Godavari river basin using the HECHMS model. Int. J. Geo-Inf., 7, 206, https://doi.org/10.3390/ IJGI7060206.

Kumar, D., A. Singh, P. Samui, and R. K. Jha, 2019: Forecasting monthly precipitation using sequential modelling. Hydrol. Sci. J., 64, 690-700, https://doi.org/10.1080/02626667.2019.1595624.

Li, C., M. Liu, Y. Hu, J. Gong, and Y. Xu, 2016: Modeling the quality and quantity of runoff in a highly urbanized catchment using storm water management model. Pol. J. Environ. Stud., 25, 1573-1581, https://doi.org/10.15244/pjoes/60721.

Li, J., F. Li, H. Li, C. Guo, and W. Dong, 2019: Analysis of rainfall infiltration and its influence on groundwater in rain gardens. Environ. Sci. Pollut. Res. Int., 26, 22 641-22 655, https:// doi.org/10.1007/s11356-019-05622-Z.

Li, J.-Z., and P. Feng, 2011: The effects of underlying surface change on floods in Zijingguan watershed. Geogr. Res., 30, 921-930, https://doi.org/10.11821/YJ2011050016.

Lin, M., X. Chen, Y. Chen, and H. Yao, 2013: Improving calibration of two key parameters in Hydrologic Engineering Center hydrologic modelling system, and analysing the influence of initial loss on flood peak flows. Water Sci. Technol., 68, 27182724, https://doi.org/10.2166/wst.2013.562.

Ling, H., C. Qian, W. Kang, C. Liang, and H. Chen, 2019: Combination of support vector machine and K-fold cross validation to predict compressive strength of concrete in marine environment. Constr. Build. Mater., 206, 355-363, https:// doi.org/10.1016/j.conbuildmat.2019.02.071.

Liu, Y., Y. Liu, and W. Wang, 2019: Inter-comparison of satelliteretrieved and Global Land Data Assimilation System-simulated 
soil moisture datasets for global drought analysis. Remote Sens. Environ., 220, 1-18, https://doi.org/10.1016/j.rse.2018.10.026.

Loague, K., C. S. Heppner, B. A. Ebel, and J. E. VanderKwaak, 2010: The quixotic search for a comprehensive understanding of hydrologic response at the surface: Horton, Dunne, Dunton and the role of concept-development simulation. Hydrol. Processes, 24, 2499-2505, https://doi.org/10.1002/HYP.7834.

Loukas, A., and M. C. Quick, 1996: Spatial and temporal distribution of storm precipitation in southwestern British Columbia. J. Hydrol., 174, 37-56, https://doi.org/10.1016/0022-1694(95) 02754-8

Manfroi, O. J., K. Koichiro, T. Nobuaki, S. Masakazu, M. Nakagawa, T. Nakashizuka, and L. Chong, 2004: The stemflow of trees in a Bornean lowland tropical forest. Hydrol. Processes, 18, 24552474, https://doi.org/10.1002/hyp.1474.

McDonough, K. R., S. L. Hutchinson, J. M. S. Hutchinson, J. L. Case, and V. Rahmani, 2018: Validation and assessment of SPoRT-LIS surface soil moisture estimates for water resources management applications. J. Hydrol., 566, 43-54, https://doi.org/10.1016/j.jhydrol.2018.09.007.

Mekanik, F., M. A. Imteaz, S. Gato-Trinidad, and A. Elmahdi, 2013: Multiple regression and artificial neural network for long-term rainfall forecasting using large scale climate modes. J. Hydrol., 503, 11-21, https://doi.org/10.1016/ j.jhydrol.2013.08.035.

Ministry of Water Resources, 2006: Guidelines for Calculating Design Flood of Water Resources and Hydropower Projects. Chinese Water Resources and Hydropower Press, 80 pp.

Mishra, S. K., M. K. Jain, R. P. Pandey, and V. P. Singh, 2003: Evaluation of AMC-dependent SCS-CN-based models using large data of small watersheds. Water Energy Int., 60, 13-23.

- R. K. Sahu, T. I. Eldho, and M. K. Jain, 2006: An improved Ia$\mathrm{S}$ relation incorporating antecedent moisture in SCS-CN methodology. Water Resour. Manage., 20, 643-660, https:// doi.org/10.1007/s11269-005-9000-4.

_ P. S. Babu, and V. P. Singh, 2007: SCS-CN method revisited. Advances in Hydraulics and Hydrology, V. P. Singh, Ed., Water Resources Publication, 36 pp.

Moustris, K. P., I. K. Larissi, P. T. Nastos, and A. G. Paliatsos, 2011 Precipitation forecast using artificial neural networks in specific regions of Greece. Water Resour. Manage., 25, 1979-1993, https://doi.org/10.1007/s11269-011-9790-5.

Nathan, R. J., and T. A. McMahon, 1990: Evaluation of automated techniques for base flow and recession analyses. Water Resour. Res., 26, 1465-1473, https://doi.org/10.1029/WR026i007p01465.

Noori, N., L. Kalin, P. Srivastava, and C. Lebleu, 2012: Effects of initial abstraction ratio in SCS-CN method on modeling the impacts of urbanization on peak flows. Proc. World Environmental and Water Resources Congress 2012, Albuquerque, NM, American Society of Civil Engineers, 329-338, http://doi.org/10.1061/ 9780784412312.036

Ouyang, Q., W. Lu, X. Xin, Y. Zhang, W. Cheng, and T. Yu, 2016: Monthly rainfall forecasting using EEMD-SVR based on phase-space reconstruction. Water Resour. Manage., 30, 23112325, https://doi.org/10.1007/s11269-016-1288-8.

Rahman, A., P. E. Weinmann, T. M. T. Hoang, and E. M. Laurenson, 2002: Monte Carlo simulation of flood frequency curves from rainfall. J. Hydrol., 256, 196-210, https://doi.org/ 10.1016/S0022-1694(01)00533-9.

Ramana, R. V., B. Krishna, S. R. Kumar, and N. G. Pandey, 2013: Monthly rainfall prediction using wavelet neural network analysis. Water Resour. Manage., 27, 3697-3711, https://doi.org/ 10.1007/s11269-013-0374-4.
Reshef, D. N., and Coauthors, 2011: Detecting novel associations in large data sets. Science, 334, 1518-1524, https://doi.org/ 10.1126/science. 1205438

Rodell, M., and Coauthors, 2004: The Global Land Data Assimilation System. Bull. Amer. Meteor. Soc., 85, 381-394, https://doi.org/ 10.1175/BAMS-85-3-381.

Saaty, T. L., 1977: A scaling method for priorities in hierarchical structures. J. Math. Psychol., 15, 234-281, https://doi.org/ 10.1016/0022-2496(77)90033-5.

Sahu, R. K., S. K. Mishra, T. I. Eldho, and M. K. Jain, 2007: An advanced soil moisture accounting procedure for SCS curve number method. Hydrol. Processes, 21, 2872-2881, https:// doi.org/10.1002/hyp.6503.

Sanyal, J., A. L. Densmore, and P. Carbonneau, 2014: Analysing the effect of land use/cover changes at sub-catchment levels on downstream flood peaks: A semi-distributed modelling approach with sparse data. Catena, 118, 28-40, https://doi.org/ 10.1016/j.catena.2014.01.015.

Schwab, M. P., J. Klaus, L. Pfister, and M. Weiler, 2017: How runoff components affect the export of DOC and nitrate: A longterm and high-frequency analysis. Hydrol. Earth Syst. Sci. Discuss., https://doi.org/10.5194/hess-2017-416.

SCS, 1956: Chapter 10: Estimation of Direct Runoff from Storm Rainfall, Supplement A. National Engineering Handbook, Section 4: Hydrology, Soil Conservation Service, USDA, 1-28. 1972: National Engineering Handbook, Section 4: Hydrology. Soil Conservation Service, U.S. Department of Agriculture, $28 \mathrm{pp}$.

Scussolini, P., J. C. J. H. Aerts, B. Jongman, L. M. Bouwer, H. C. Winsemius, H. De Moel, and P. J. Ward, 2016: FLOPROS: An evolving global database of flood protection standards. Nat. Hazards Earth Syst. Sci., 16, 1049-1061, https://doi.org/ 10.5194/nhess-16-1049-2016.

Shan, S., 2016: Machine Learning Models and Algorithms for Big Data Classification: Thinking with Examples for Effective Learning. Integrated Series in Information System, Vol. 36, Springer, 359 pp.,https://doi.org/10.1007/978-1-4899-7641-3.

Shi, Z. H., L. D. Chen, N. F. Fang, D. F. Qin, and C. F. Cai, 2009: Research on the SCS-CN initial abstraction ratio using rainfall-runoff event analysis in the Three Gorges Area, China. Catena, 77 (1), 1-7, https://doi.org/10.1016/ j.catena.2008.11.006.

Simanton, J. R., R. H. Hawkins, M. Mohseni-Saravi, and K. G. Renard, 1996: Runoff curve number variation with drainage area, Walnut Gulch, Arizona. Trans. ASAE, 39, 1391-1394, https://doi.org/10.13031/2013.27630.

Singh, P. K., S. K. Mishra, R. Berndtsson, M. K. Jain, and R. P. Pandey, 2015: Development of a modified SMA based MSCS-CN model for runoff estimation. Water Resour. Manage., 29, 4111-4127, https://doi.org/10.1007/s11269015-1048-1.

Tang, W. G., and S. K. Carey, 2017: HydRun: A MATLAB toolbox for rainfall-runoff analysis. Hydrol. Processes, 31, 2670-2682, https://doi.org/10.1002/hyp.11185.

Tarasova, L., S. Basso, M. Zink, and R. Merz, 2018: Exploring controls on rainfall-runoff events: 1 . Time series-based event separation and temporal dynamics of event runoff response in Germany. Water Resour. Res., 54, 7711-7732, https://doi.org/ 10.1029/2018WR022587.

Tayfur, G., and V. P. Singh, 2008: Closure to "ANN and fuzzy logic models for simulating event-based rainfall-runoff" J. Hydrol. Eng., 134, 1400-1401, https://doi.org/10.1061/(ASCE)07339429(2008)134:9(1400.2). 
USACE, 2008: HEC-Hydrologic modeling system (HEC-HMS)application guide. U.S Army Corps of Engineers, 118 pp., https:/www.hec.usace.army.mil/software/hec-hms/documentation/ HEC-HMS_Applications_Guide_March2008.pdf.

Vapnik, V., 1995: The Nature of Statistical Learning Theory. Springer, $334 \mathrm{pp}$.

Vissa, N. K., P. C. Anandh, M. M. Behera, and S. Mishra, 2019: ENSO-induced groundwater changes in India derived from GRACE and GLDAS. J. Earth Syst. Sci., 128, 115, https:// doi.org/10.1007/s12040-019-1148-z.

Wang, A., D. P. Lettenmaier, and J. Sheffield, 2011: Soil moisture drought in China, 1950-2006. J. Climate, 24, 3257-3271, https:// doi.org/10.1175/2011JCLI3733.1.

Wang, W., W. Cui, X. Wang, and X. Chen, 2016: Evaluation of GLDAS-1 and GLDAS-2 forcing data and Noah model simulations over China at the monthly scale. J. Hydrometeor., 17, 2815-2833, https://doi.org/10.1175/JHM-D-15-0191.1.

Weeink, W., 2010: Thresholds for flood forecasting and warning. M.S. thesis, Water Engineering and Management, University of Twente, $88 \mathrm{pp}$.

Woodward, D. E., R. H. Hawkins, R. Jiang, A. T. Hjelmfelt Jr., J. A. Van Mullem, and Q. D. Quan, 2003: Runoff curve number method: Examination of the initial abstraction ratio. World Water and Environmental Resources Congress, Philadelphia, PA, American Society of Civil Engineers, 691-700.

Xing, W., W. Wang, Q. Shao, B. Yong, C. Liu, X. Feng, and Q. Dong, 2018: Estimating monthly evapotranspiration by assimilating remotely sensed water storage data into the extended Budyko framework across different climatic regions. J. Hydrol., 567, 684-695, https://doi.org/10.1016/ j.jhydrol.2018.10.014.

Young, R. A., C. A. Onstad, D. D. Bosch, and W. P. Anderson, 1989: AGNPS: A nonpoint-source model for evaluating agricultural watersheds. J. Soil Water Conserv., 44, 168-173.

Younis, S. M. Z., and A. Ammar, 2018: Quantification of impact of changes in land use-land cover on hydrology in the upper Indus Basin, Pakistan. Egypt. J. Remote Sens. Space Sci., 21, 255-263, https://doi.org/10.1016/ J.EJRS.2017.11.001.

Yuan, X., Z. Ma, M. Pan, and C. Shi, 2015: Microwave remote sensing of short-term droughts during crop growing seasons. Geophys. Res. Lett., 42, 4394-4401, https://doi.org/10.1002/ 2015 GL064125. 